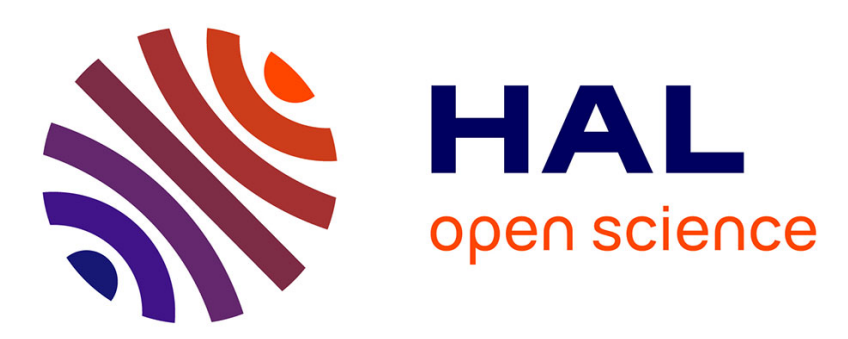

\title{
An overview on the removal of synthetic dyes from water by electrochemical advanced oxidation processes.
}

\author{
P V Nidheesh, Minghua Zhou, Mehmet A. Oturan
}

\section{To cite this version:}

P V Nidheesh, Minghua Zhou, Mehmet A. Oturan. An overview on the removal of synthetic dyes from water by electrochemical advanced oxidation processes.. Chemosphere, 2018, 197 (210-227.), 10.1016/j.chemosphere.2017.12.195 . hal-01721053

\section{HAL Id: hal-01721053 \\ https://hal.science/hal-01721053}

Submitted on 1 Mar 2018

HAL is a multi-disciplinary open access archive for the deposit and dissemination of scientific research documents, whether they are published or not. The documents may come from teaching and research institutions in France or abroad, or from public or private research centers.
L'archive ouverte pluridisciplinaire HAL, est destinée au dépôt et à la diffusion de documents scientifiques de niveau recherche, publiés ou non, émanant des établissements d'enseignement et de recherche français ou étrangers, des laboratoires publics ou privés. 


\title{
An overview on the removal of synthetic dyes from water by electrochemical advanced oxidation processes
}

\author{
P. V. Nidheesh ${ }^{1}$, Minghua Zhou ${ }^{2}$, Mehmet A. Oturan ${ }^{3, *}$
}

${ }^{1}$ CSIR-National Environmental Engineering Research Institute, Nagpur, Maharashtra, India

${ }^{2}$ Key Laboratory of Pollution Process and Environmental Criteria, Ministry of Education, Tianjin Key Laboratory of Urban Ecology Environmental Remediation and Pollution Control, College of Environmental Science and Engineering, Nankai University, Tianjin 300350, P. R. China.

${ }^{3}$ Université Paris-Est, Laboratoire Géomatériaux et Environnement, (LGE), , EA 4508, UPEM, 5 Bd Descartes, 77454 Marne-la-Vallée Cedex 2, France

Paper submitted for publication in SI: EAOPs-POPs, Chemosphere

*Corresponding author:

Email: Mehmet.Oturan@ univ-paris-est.fr (Mehmet A. Oturan) Tel.: +33 (0)1 49329065 


\section{Abstract}

2 Wastewater containing dyes are one of the major threats to our environment. Conventional 3 methods are insufficient for the removal of these persistent organic pollutants. Recently much 4 attention has been received for the oxidative removal of various organic pollutants by 5 electrochemically generated hydroxyl radical. This review article aims to provide the recent 6 trends in the field of various electrochemical advanced oxidation processes (EAOPs) used for

7 removing dyes from water medium. The characteristics, fundamentals and recent advances in 8 each processes namely anodic oxidation, electro-Fenton, peroxicoagulation, fered Fenton, 9 anodic Fenton, photoelectro-Fenton, sonoelectro-Fenton, bioelectro-Fenton etc. have been 10 examined in detail. These processes have great potential to destroy persistent organic 11 pollutants in aqueous medium and most of the studies reported complete removal of dyes 12 from water. The great capacity of these processes indicates that EAOPs constitute a 13 promising technology for the treatment of the dye contaminated effluents.

15 Keywords: Dye removal, Electrochemical advanced oxidation, Decolorization, 16 Mineralization, Hydroxyl radicals, Wastewater treatment 


\section{Introduction}

Water pollution due to various industrial effluents is a global environmental problem.

Due to the rapid industrialization, the use of coloring chemicals like dyes also increases day by day. Overall, 40,000 dyes and pigments with more than 7,000 different chemical structures have been reported recently (Demirbas, 2009). Production of dyestuff and pigments annually across the world is more than 700,000 tonnes and in India itself it is close to 80,000 tonnes (Mathur et al., 2005; Gong et al., 2007; Mane et al., 2007). Among this 10,000 different types of dyes and pigments are being manufactured annually across the world (Ponnusami et al., 2008). These dyes are chemically, photolytically and biologically highly stable and are highly persistent in nature (Suteu and Bilba, 2005). Various industries like textile, leather, food, cosmetic, paper, pharmaceutical etc. are using variety of synthetic dyes. Among these industries, textile industries are the largest consumer of dying stuffs and pigments and produces large amount effluents after dyeing process. For example, 1.5 million liters per day of effluent are discharging into natural water bodies from an average mill producing $60 \times 10^{4} \mathrm{~m}$ of fabric (COINDS, 2000). This wastewater contains various kinds of pollutants apart from dyes and most of them are hazardous. Depending on the textile processes, effluents generated from the industry contains various types of solvents, salts, detergents etc. apart from many types of dyes (Barredo-Damas et al., 2006). Typical characteristics of the effluent generated from textile industries are given in Table 1. Among these contaminants, removal of dyes from the wastewater needs to be a special attention.

The effluents containing dyes are one of the major threats to environment. Even in low concentrations, the dyes are highly visible (esthetic pollution) and affect the aquatic life and food chain (chemical pollution) (Namasivayam and Kavitha, 2002; Malik, 2003). However, the average concentration of dyes in a textile wastewater is around $300 \mathrm{mg} \mathrm{L}^{-1}$ (Couto, 2009). 
43 distress biological process in the water medium and provide an aesthetically displeasing appearance (Arivoli et al., 2009). Reduced light penetration with the introduction of colored wastewater reduces the photosynthetic activity within the water body and this also affect the symbiotic process (Ju et al., 2008).

Table 1 Characteristics of textile wastewater. Reprinted with permission from Sandya et al. (2008), Copyright 2007, Elsevier.

\begin{tabular}{lc}
\hline \multicolumn{1}{c}{ Parameters } & Concentration \\
\hline Solution $\mathrm{pH}$ & $9.5-12.5$ \\
Total Suspended Solids $\left(\mathrm{mg} \mathrm{L}^{-1}\right)$ & $60-416$ \\
Total Dissolved Solids $\left(\mathrm{mg} \mathrm{L}^{-1}\right)$ & $4500-12800$ \\
Total Organic Carbon $\left(\mathrm{mg} \mathrm{L}^{-1}\right)$ & $26390-73190$ \\
Biochemical Oxygen Demand $\left(\mathrm{mg} \mathrm{L}^{-1}\right)$ & $25-433$ \\
Chemical Oxygen Demand $\left(\mathrm{mg} \mathrm{L}^{-1}\right)$ & $1835-3828$ \\
Aromatic Amines (mg L & $20-75$ \\
Ammonia $\left(\mathrm{mg} \mathrm{L}^{-1}\right)$ & $2-3$ \\
Chloride $\left(\mathrm{mg} \mathrm{L}^{-1}\right)$ & $1200-1375$ \\
Sulphate $\left(\mathrm{mg} \mathrm{L}^{-1}\right)$ & $700-2400$ \\
\hline
\end{tabular}

The hazardous, toxic and carcinogenic natures of dyes are also well known. Physiological disorders in aquatic organisms happen by the consumption of dyes in textile effluents via food chain (Karthikeyan et al., 2006). Some of the azo dyes are responsible for causing bladder cancer in humans and chromosomal aberration in mammalian cells 54 (Mendevedev, 1988; Percy et. al., 1989). Cytotoxicity of reactive dyes (three monochlortriazinyl dyes: yellow, red and blue with different concentrations) using human keratinocyte HaCaT cells in vitro was investigated by Klemola et al. (2007) and the mean

57 inhibitory concentration values after $72 \mathrm{~h}$ of exposure was measured as $237 \mu \mathrm{g} \mathrm{mL} \mathrm{L}^{-1}$ for 58 yellow dye, $155 \mu \mathrm{g} \mathrm{mL}^{-1}$ for red dye and $278 \mu \mathrm{g} \mathrm{mL}^{-1}$ for blue dye. Similarly, spermatozoa 
motility inhibition test of these dyes showed the mean inhibitory concentration values after $24 \mathrm{~h}$ of exposure as $135 \mu \mathrm{g} \mathrm{mL} L^{-1}$ for yellow dye, $\mu \mathrm{g} \mathrm{mL} L^{-1}$ for red dye and $127 \mu \mathrm{g} \mathrm{mL}^{-1}$ for blue dye (Klemola et al., 2006). Frame-shift mutation and base pair substitution in Salmonella in the presence of CI disperse blue was observed by Umbuzeiro et al. (2005). Experimental investigations of Bae and Freeman (2007) reported that C.I. Direct Blue 218 is very toxic to daphnids. The $50 \%$ of mortality of daphnids was observed for concentrations of 1-10 mg L $\mathrm{m}^{-1}$ of C.I. Direct Blue 218 after $48 \mathrm{~h}$. Impact of textile effluents on a proteinous edible fresh water fish Mastacembelus Armatus was examined by Karthikeyan et al. (2006) and they observed a decrease in $\mathrm{Na}^{+}$and $\mathrm{Cl}^{-}$concentrations and increase in $\mathrm{K}^{+}, \mathrm{Mg}^{2+}$ and $\mathrm{Ca}^{2+}$ concentrations after $35 \mathrm{~d}$ of Acid Blue 92 exposure. The toxicity of the textile dye industry effluent on freshwater female crab, Spiralothelphusa hydrodroma was investigated by Sekar et al. (2009). The authors observed a decrease in protein, carbohydrate and lipid contents in ovary, spermatheca, muscle, hepatopancreas, gill, brain, thoracic ganglia and eyestalks at $30 \mathrm{~d}$ of sublethal $(69.66 \mathrm{ppm})$ concentration of textile dye industry effluent exposure. Mathur et al. (2005) tested the mutagenic activity of seven dyes by Ames assay, using strain TA 100 of Salmonella typhimurium and reported that except violet dye, all are mutagenic. Among these mutagenic dyes, Congo red and royal blue dyes are moderately mutagenic while bordeaux is highly mutagenic or extremely mutagenic. Similarly, effect of malachite green on immune and reproductive systems was observed by Srivastava et al. (2004). The authors also observed the potential genotoxic and carcinogenic nature of the mentioned basic dye.

These non-exhaustive examples highlight how much the presence of the dyes in water is harmful to the aquatic environment. Therefore, removal of dyes from aqueous medium is an important environmental issue in the environmental safety point of view. 


\section{Electrochemical advanced oxidation processes for dye removal}

Various treatment techniques such as adsorption, coagulation, filtration, electrocoagulation, photolysis, sonolysis, biodegradation, wet land treatment, ozonation, photocatalysis, membrane filtration etc. have been used for removing synthetic dyes from aqueous solution. Advantages and disadvantages of dye removal methods have been

90 discussed in detail (Crini, 2006; Martinez-Huitle and Brillas, 2009; Nidheesh et al., 2013).

91 Based on the principle mechanism behind the removal of dyes, these processes can be divided into two broad classes: Separative (physical, and physicochemical) methods, and degradative (chemical and biological) methods. The schematic diagram of the various methods used for the dye removal is shown in Fig. 1. Most of the methods used for dye removal are separation process and the main disadvantage of these processes is the disposal of dye containing sludge as in coagulation process, dye sorbed adsorbents and concentrated dye solution as in membrane processes. In contrary to this, complex dye compounds undergo a series of degradation in chemical degradation methods. In the case of use of advanced oxidation processes, degradation procedure advance until ultimate oxidation degree, i.e.

100 mineralization of organic pollutants. These methods produce carbon dioxide, water and various inorganic ions (following heteroatoms presents at the starting organic pollutants) as the final products. 


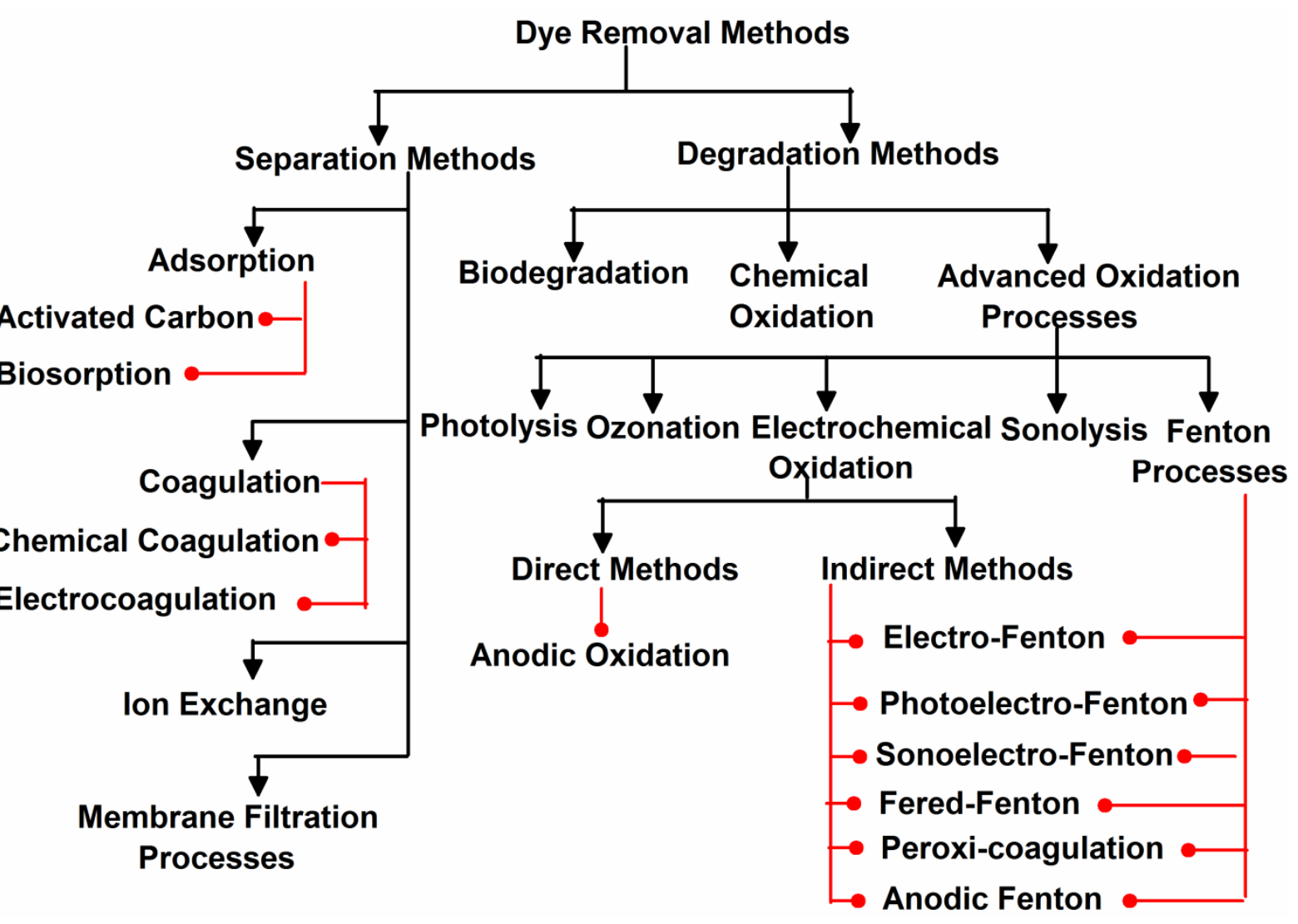

Fig. 1 Schematic representation of method used in dye removal from water

Among various degradation techniques, advanced oxidation processes (AOPs) received great attention for the efficient degradation of dyes, during recent years (Martinez-Huitle et al., 2009, Oturan and Aaron, 2014). These processes are based on the production of highly reactive oxidants, mainly hydroxyl radical $\left({ }^{\circ} \mathrm{OH}\right)$. This radical is the second most powerful oxidizing agent (after fluorine) with a redox potential of $E^{\circ}\left({ }^{\circ} \mathrm{OH} / \mathrm{H}_{2} \mathrm{O}\right)=2.8 \mathrm{~V} / \mathrm{SHE}$. Once these radicals are produced in situ, they attack organic pollutants with high reaction rates through following three different ways (Oturan, 2000; Brillas et al., 2009; Sirés et al., 2014):

113 electron transfer (redox reaction) (Eq. (1)), $\mathrm{H}$ atom abstraction (dehydrogenation) (Eq. (2)), and electrophilic addition to $\pi$ systems (hydroxylation) (Eq. (3)). These reactions produce organic radicals and start a radical chain including reactions with oxygen (formation of peroxy radicals) and formed reaction intermediates undergo further oxidation reactions with 
generated oxidizing agents ( $\mathrm{OH}, \mathrm{HO}_{2}^{\circ}, \mathrm{H}_{2} \mathrm{O}_{2} \ldots$ ) until the complete mineralization of organic pollutants.

$$
\begin{aligned}
& { }^{\bullet} \mathrm{OH}+\mathrm{RX} \rightarrow \mathrm{RX}^{+\bullet}+\mathrm{OH}^{-} \\
& { }^{\bullet} \mathrm{OH}+\mathrm{RH} \rightarrow \mathrm{R}^{\bullet}+\mathrm{H}_{2} \mathrm{O} \\
& { }^{\circ} \mathrm{OH}+\mathrm{PhX} \rightarrow \mathrm{PhX}(\mathrm{OH})^{\bullet}
\end{aligned}
$$

Among the AOPs, electrochemical advanced oxidation processes (EAOPs) that have been developed during the last decade have generated great interest for the abatement of various persistent organic pollutants including synthetic dyes. EAOPs use electrolytically produced hydroxyl radicals for the mineralization of organic pollutants. Based on the production of hydroxyl radicals in the electrolytic system, EAOPs can be divided into two categories: direct and indirect EAOPs as shown in Fig. 1. In the case of direct EAOPs, hydroxyl radicals are produced on the anode surface by direct oxidation of water according to the Eq. (4):

$$
\mathrm{M}+\mathrm{H}_{2} \mathrm{O} \rightarrow \mathrm{M}\left({ }^{\circ} \mathrm{OH}\right)+\mathrm{H}^{+}+\mathrm{e}^{-}
$$

with M: anode material. The production rate and extent depend on the nature (catalytic activity) of anode material, diffusion rate of organic pollutants on the active sites of anode and applied current density (Panizza and Cerisola 2009; Miled et al., 2010). The great advantage of this process is to not require the external addition of reagents for the production of hydroxyl radicals. In the case of indirect EAOPs, the generation of hydroxyl radicals is based on the Fenton chemistry including in situ electrochemical generation (electro-Fenton) or externally addition of the one of the reagent $\left(\mathrm{H}_{2} \mathrm{O}_{2}\right.$ or ferrous iron) (fered-Fenton). Mostly $\mathrm{H}_{2} \mathrm{O}_{2}$ is in situ produced at the cathode thanks to the use of an adequate electrode material. Hydroxyl radicals are produced by the reaction between electrolytically generated or externally added $\mathrm{H}_{2} \mathrm{O}_{2}$ and anodically generated or externally added ferrous iron (Brillas et 
al., 2009). Electro Fenton process constitutes an excellent example of indirect EAOPs, in which hydroxyl radicals are produced by the reaction between electrochemically in situ generated $\mathrm{H}_{2} \mathrm{O}_{2}$ and electrocatalytically regenerated ferrous ion.

EAOPs have several advantages over conventional treatment techniques. The main advantage of the EAOPs is environmental compatibility as the main reagent for all the EAOPs is electron, which is an inbuilt clean species (Peralta-Hernández et al., 2009). Other advantages are related to their versatile nature, higher pollutant removal efficiency, operational safety and amenability of automation (Jüttner et al., 2000; Anglada et al., 2009, Sirés et al., 2014). In addition, the presence of salt (e.g., $\mathrm{NaCl}$ ) in wastewater could help to improve process efficiency and reduce energy consumption (Zhou et al., 2011a, 2011b).

The main aim of this review is to present a general review on the application of EAOPs for the removal of dyes from aqueous solution. Special attention is made on fundamental reactions involved of each EAOP to provide clear idea on its characteristics and oxidation capacity.

\section{Direct EAOPs}

\subsection{Anodic Oxidation}

Anodic oxidation (AO) is the most popular direct EAOPs; it works based on the hydroxyl radical production at the anode surface (Panizza and Cerisola, 2009). The process is 
chemisorbed in the case of active anode like Pt or DSA and are less available. The production of hydroxyl radicals is promoted by high $\mathrm{O}_{2}$ evolution overvoltage anodes such as borondoped diamond (BDD) thin film anodes. In these latter cases, hydroxyl radicals are physisorbed and consequently more available for oxidation of organics. Various researchers well explained the organic pollutant degradation mechanism in AO process in the case of metal oxide $\left(\mathrm{MO}_{\mathrm{x}}\right)$ anodes (Comninellis, 1994; Scialdone, 2009). Heterogeneous hydroxyl radicals $\mathrm{MO}_{\mathrm{x}}\left(\mathrm{HO}^{\circ}\right)$ are mainly formed by the oxidation of water (Eq. (5)). The adsorbed radicals result in the production of chemisorbed oxygen (Eq. (6)) or oxygen evolution (Eq. (7)). The chemisorbed oxygen also undergoes further reaction and produces oxygen as in Eq. and Battisti, 1996): electrochemical conversion: degradation of persistent organic pollutants complete mineralization of the organic pollutants and the chemisorbed oxygen

into biodegradable byproducts such as short-chain carboxylic acids, and electrochemical combustion or incineration (complete mineralization of organic pollutants into $\mathrm{CO}_{2}, \mathrm{H}_{2} \mathrm{O}$ and inorganic ions). Between the oxidants produced in $\mathrm{AO}$ electrolytic cell, $\mathrm{MO}_{\mathrm{x}}\left(\mathrm{HO} \mathrm{O}^{\circ}\right.$ ) causes the $\left(\mathrm{MO}_{\mathrm{x}}\left(\mathrm{HO}^{\circ}\right)\right)$ causes the selective oxidation of organic pollutants (Chen, 2004). This 
difference in the oxidation ability of these two oxidants is mainly due to their different oxidation potentials. Overall, AO process can be defined as the direct EAOPs in which the degradation of the organic pollutants occurs mainly by the adsorbed hydroxyl radicals produced by the water oxidation in the presence of high $\mathrm{O}_{2}$ overvoltage anodes.

Compared with other treatment processes, AO process has several advantages. The major three advantages of AO process are (Chen et al., 2003): rapid degradation of pollutants, elevated removal efficiency, and easy operation. Apart from this, high efficiency at various solution $\mathrm{pH}$ is also promotes the practical implementation of AO process. In general hydroxyl radical formation is better in acidic media but the difference is not significant. Thus it was reported that heterogeneous hydroxyl radicals are also formed at $\mathrm{pH} \geq 10$ (Sirés et al., 2006; Özcan et al., 2008a). Even though complete mineralization of clofibric acid (Sirés et al., 2006) and 4,6-dinitro-o-cresol (Flox et al., 2005) at pH 12 was reported.

In AO, selection of anode affects significantly the efficiency of the process. There are two types of anodes in AO process: active and non-active anodes. This differentiation is mainly based on the reaction of anode material with adsorbed hydroxyl radicals. In the case of active anodes, formation of higher oxides or super oxides occurs by the reaction of anode with hydroxyl radicals. This reaction happens when the anode has higher oxidation potential above the standard potential required for the oxygen evolution (Migliorini et al., 2011). The anodes like $\mathrm{Pt}, \mathrm{IrO}_{2}, \mathrm{SnO}_{2}$ and $\mathrm{RuO}_{2}$ are the examples of active anodes. On the other hand, hydroxyl radicals are physically sorbed on the non-active anodes and the mineralization of organic pollutants occurs mainly by the direct reaction of physisorbed hydroxyl radicals. These electrodes do not contribute any direct anodic reaction of organic pollutants and do not impart any catalytic site for the effective pollutant sorption (Migliorini et al., 2011). BDD electrode is the best example of non-active anodes. 
214 For example, BDD anode was found to be the best electrode for the mineralization of various

215 persistent organic pollutants. This is mainly due to its greater $\mathrm{O}_{2}$ overvoltage (which

216 increases the hydroxyl radical production rate), its wide potential window, low background

217 current and very low activity for $\mathrm{O}_{2}$ evolution reaction (Braga et al., 2010; Migliorini et al.,

218 2011; Oturan et al., 2012; Haidar et al., 2013). The removal of adsorbed organics on the BDD

219 surface is also easy. In most of the cases, rinsing with appropriate solvent is required for the

220 effective cleaning of BDD surface (Migliorini et al., 2011). The degradation of carboxylic

221 acids by Pt is also very difficult. But the degradation of these acids is feasible with BDD

222 anode, thanks to the efficiency of $\mathrm{BDD}\left({ }^{\circ} \mathrm{OH}\right)$ and also the strong oxidants such as

223 peroxodisulfate and $\mathrm{O}_{3}$ formed during oxidation process according to the following reactions

224 (Murugananthan et al., 2007; Flox et al., 2009; Li et al., 2010a).

Recently a great attention has been paid to improve the efficiency of anodes by using appropriate substrate (Wang et al., 2013; Hu et al., 2014). The selection of suitable substrate is also an important parameter. A substrate should have good electrical conductivity, sufficient mechanical strength, and electrochemical inertness or easy formation of protective films on substrate surfaces by passivation (Chen et al., 2003). For example, various substrates like $\mathrm{Si}, \mathrm{Ti}, \mathrm{Nb}$ etc. were used as substrate for BDD anode. The substrate used for the BDD anode has been classically $\mathrm{Si}$. But, $\mathrm{Si}$ is difficult to use as a substrate for electrode due to its fragile nature and its conductivity is strongly dependent on the experimental environments 236 (Sun et al., 2011). Among the various substrates, the suitable substrate for the BDD anode 
was found as Ti (Chen et al., 2003; Sun et al., 2011). Also, the $\mathrm{O}_{2}$ overvoltage potential of Ti/BDD is higher than that of Si/BDD anode (Chen, 2004). researchers. Faouzi et al. (2007) reported a total degradation and mineralization of alizarin red S by AO process using BDD anode. Similarly, complete mineralization of methyl orange in the presence of in situ microwave activated Pt was observed by Zhao et al. (2009). Color and COD removals from real textile effluents using BDD anode was studied by MartínezHuitle et al. (2012) and they observed an effective reduction in color and COD after $15 \mathrm{~h}$ of electrolysis. Yavuz and Shahbazi (2012) used bipolar trickle tower reactor containing BDD anode for the removal of reactive black 5 in a continuous flow mode operation and achieved 97\% color, $\sim 51 \%$ COD and $29.3 \%$ TOC removal at the optimal conditions, along with the reduction in toxicity. The oxidation of methyl orange using BDD anode in a 3 L capacity electrolytic cell was studied by Ramírez et al. (2013) and obtained a 94\% decolorization and 63.3\% TOC removal efficiencies at the optimal conditions. Complete color and COD removals from an aqueous solution containing methylene blue in the presence of BDD anode was observed by Panizza et al. (2007). Degradation of three azoic dyes, Congo red, methyl orange, and eriochrome black $\mathrm{T}$, using conductive-diamond anodes was investigated by Canizares et al. (2006) and concluded that the efficiency of the system depends only on the initial concentration of dye.

Nava et al. (2008) compared the color and COD removal efficiencies of various electrode materials for the abatement of alphazurine A dye and observed almost complete mineralization of dye with $\mathrm{Pb} / \mathrm{PbO}_{2}$ and $\mathrm{Si} / \mathrm{BDD}$ electrodes, while $\mathrm{Ti} / \mathrm{IrO}_{2}$ disfavored such process. Similarly complete removal of color and COD induced by the alphazurine A using BDD anode was observed by Bensalah et al. (2009). Aquino et al. (2013) used Si/BDD anode for the degradation of reactive red 141 in a filter-press flow cell and applied response surface 
methodology to determine the effects of different operating parameters on color, COD and TOC removals. The performances of $\mathrm{Ti}-\mathrm{Pt} / \beta-\mathrm{PbO}_{2}$ and $\mathrm{BDD}$ anodes on the removal of reactive orange 16 in a filter press reactor were investigated by Andrade et al. (2009). The study concluded that even though complete dye removal is achieved by both the electrodes, BDD provided better results than Ti-Pt/ $\beta-\mathrm{PbO}_{2}$ due to less energy consumption. Abdessamad et al. (2013) compared the efficiency of monopolar and bipolar BDD electrodes for the removal of alizarin blue black B and concluded that the dye degradation efficiency of bipolar AO system is 1.2 times higher than that of monopolar AO system. Chen et al. (2003) were found that dye removal efficiency of Ti/BDD anode was higher than that of $\mathrm{Ti}^{2} / \mathrm{Sb}_{2} \mathrm{O}_{5}-\mathrm{SnO}_{2}$ anode. Also, Ti/BDD anode has higher dye removal efficiency in the cases of alizarin red $\mathrm{S}$ (Sun et al., 2011), orange II and reactive red HE-3B (Chen et al., 2003). The dye removal efficiencies of BDD and $\mathrm{PbO}_{2}$ electrodes were compared by Panizza and Cerisola (2008) and observed a higher oxidation rate and higher current efficiency in the case of BDD anode than that of $\mathrm{PbO}_{2}$ anode. At the same time, methyl orange degradation efficiency of $\mathrm{TiRuSnO}_{2}$ is very much less than that of $\mathrm{BDD}$ and $\mathrm{PbO}_{2}$ anode (Labiadh et al., 2016). Partial removal of the dye was achieved by using $\mathrm{TiRuSnO}_{2}$ anode, but complete dye removal was also observed with other anodes. Even though, both anodes are efficient for the complete dye removal, complete mineralization was occurred only in the presence of BDD anode. electrodeposition and used it for the removal of methylene blue. The authors observed a 100\% dye and 72.7\% COD removal after 120 min of electrolysis. Similarly, An et al. (2012) synthesized $\mathrm{TiO}_{2}-\mathrm{NTs} / \mathrm{Sb}-\mathrm{SnO}_{2} / \mathrm{PbO}_{2}$ anode for the abatement of C.I. reactive blue 194 and reported that the prepared electrode has a high decolorization and mineralization ability. Recent study by do Vale-Júnior et al. (2016) demonstrates that Sn-Cu-Sb alloy anode 
The authors observed complete acid blue-29 removal and mineralization after $300 \mathrm{~min}$ and 600 min of electrolysis, respectively.

Effect of boron doping in BDD anode on dye removal was investigated by Migliorini et al. (2011) and reported that highly boron doped electrodes has the higher reactive orange 16 removal efficiency. Similar result has been observed by Bogdanowicz et al. (2013).

Rodriguez et al. (2009) observed two different oxidation mechanisms for acid yellow 1 in the presence of BDD anodes. The oxidation of dye depends more on its initial concentration. At the lower dye concentration, the oxidation process followed pseudo first order kinetics and under the control of mass transport. While, at the higher dye concentrations, the degradation of acid yellow 1 followed zero order kinetics and reaction kinetics was controlled by charge transfer.

Panizza and Cerisola (2008) observed the $\mathrm{pH}$ independent methyl red oxidation in the range of 3 to 7. Similarly, insignificant effect of initial solution $\mathrm{pH}$ on dye removal by AO process using Ti/SnO ${ }_{2}-\mathrm{Sb} / \mathrm{PbO}_{2}$ was observed by Song et al. (2010). Similar result has been reported by Petrucci and Montanaro (2011). The authors observed that even though the color removal was affected by the change in $\mathrm{pH}$, the mineralization ability of BDD anode was not altered with the solution $\mathrm{pH}$.

Supporting electrolyte also plays an important role on the dye removal mechanism. Aquino et al. (2012) studied the effects of the salt (supporting electrolyte) addition for the removal of acid blue 62, reactive red 141, direct black 22, and disperse orange 29 using conductive-diamond anodes. The authors observed a mediated electrooxidation of dyes in the presence of chloride addition. At the same time, the removal of dyes by the addition of sulphate as supporting electrolyte is mainly by the attack of hydroxyl radicals, generated from BDD anode. Zhou et al. (2011a) compared the methyl orange degradation by electrochemical 
oxidation using BDD and mixed metal oxide anodes and found enhanced dye removal in the presence of $\mathrm{NaCl}$, which is mainly attributed to the co-action of mediated oxidation from active chlorine species.

The functional groups presents in the dyes also affects the efficiency of the electrolytic system. Saez et al. (2007) compared the alizarin red and eriochrome black T removals in the presence of BDD anode. The authors reported two different oxidation mechanisms for dye removals, even though complete COD and color removals from both dye wastewaters were observed. The removal of alizarin red was mainly due to hydroxyl radical mediated oxidation and controlled by mass transfer process, while the removal of eriochrome black $\mathrm{T}$ was mainly due to electrolytically generated reagents like peroxodisulphate.

\section{Indirect EAOPs}

Production of hydroxyl radicals in indirect EAOPs is accomplished by the in situ production or external addition of chemicals. Fenton based EAOPs are the best examples of indirect EAOPs. The following sections discuss the applications and recent advances in these processes for the removal of dyes from aqueous medium.

\subsection{Electro-Fenton (EF) process}

During the last decade EF process received much attraction among other processes.

329 This is an economically and environmentally friendly process to remove efficiently toxic and/or persistent organic pollutants from water. Oturan and Brillas groups reported the principles of the EF process in the starting of 2000 (Oturan and Pinson 1995; Brillas et al., 1996; Oturan, 2000; Brillas et al., 2000). EF process is an attractive tool and its interest is mainly due to its high degrading effectiveness of persistent organic pollutants, fast pollutant 
removal rate and environmental compatibility (Oturan et al., 2000; Brillas et al., 2009;

Nidheesh et al., 2013; Sirés et al., 2014; Vasudevan and Oturan 2014).

EF process works based on the in situ electrogeneration of Fenton's reagent, a mixture

of $\mathrm{H}_{2} \mathrm{O}_{2}$ and $\mathrm{Fe}^{2+}$ which is the origin of the Fenton's reaction (Eq. (15)) to generate hydroxyl radicals. Hydrogen peroxide is generated continuously at the cathode surface from the two electron reduction of $\mathrm{O}_{2}$ in the acidic medium (Eq. (14)) (Oturan et al., 2008a; Özcan et al., 2009a; Nidheesh and Gandhimathi, 2012). Supply of oxygen near the cathode during EF treatment is required for fulfilling the continuous production of hydrogen peroxide in the electrolytic system. The addition of a catalytic amount of a ferrous salt (to produce $\mathrm{Fe}^{2+}{ }^{2}$ ions) into the solution leads to production of ${ }^{\bullet} \mathrm{OH}$ according to Fenton's reaction (Eq. (15)).

Catalysis of the Fenton's reaction by electrochemical regeneration of ferrous ion is an important advantage of EF process compared to conventional Fenton process (Oturan et al., 2011; Moreira et al., 2013). Indeed, the optimal pH value for Fenton's reaction and Fenton related processes is about 3 (Brillas et al., 2009). At this $\mathrm{pH}$, the predominant species of iron is $\mathrm{Fe}(\mathrm{OH})^{2+}$ (Eq. 16) (Özcan et al., 2013). The $\mathrm{Fe}^{3+}$ produced by Fenton's reaction remains under the form of $\mathrm{Fe}(\mathrm{OH})^{2+}$ and undergoes cathodic reduction to produce ferrous ion according to Eq. (17) (Özcan et al., 2008b). Apart from this main source, ferrous ions are regenerated in the EF process via Fenton's chain reactions as in Eqs. (18-20) (Oturan et al., 2004; Oturan et al., 2010a).

$$
\mathrm{Fe}^{3+}+\mathrm{H}_{2} \mathrm{O} \rightarrow \mathrm{Fe}(\mathrm{OH})^{2+}+\mathrm{H}^{+}
$$




$$
\mathrm{Fe}^{3+}+\mathrm{HO}_{2}^{\bullet} \rightarrow \mathrm{Fe}^{2+}+\mathrm{H}^{+}+\mathrm{O}_{2}
$$

$$
\mathrm{Fe}^{3+}+\mathrm{R}^{\bullet} \rightarrow \mathrm{Fe}^{2+}+\mathrm{R}^{+}
$$

where $\mathrm{R}^{\bullet}$ is organic radical.

Also, in overall, EF process results the production of two moles of hydroxyl radicals from 0.5 moles of oxygen as in Eq. (21) (Oturan et al., 2001) showing the catalytic behavior of the process.

An insignificant change in solution $\mathrm{pH}$ with electrolysis time is the other advantage of reaction by the protons produced via water oxidation at the anode (El-Desoky et al., 2010) and carboxylic acids generated during the oxidation process (Oturan and Aaron, 2014). of EF process. This is mainly due to its wide range of electrochemical activity for $\mathrm{O}_{2}$ reduction and low catalytic activity for $\mathrm{H}_{2} \mathrm{O}_{2}$ decomposition (Panizza and Cerisola, 2001). Also, the porosity of carbonaceous material is very high, in particular $3 \mathrm{D}$ carbon materials like carbon felt or graphite felt are of high porosity. These pores are useful for the sorption of oxygen gas supplied near the cathode surface and consequently results in higher amount of hydrogen peroxide generation. Various carbonaceous materials like carbon-felt (Oturan, 2000; Murati et al., 2012), reticulated vitreous carbon sheet (El-Desoky et al., 2010; Ghoneim et al., 2011), activated carbon fiber (Wang et al., 2010), graphite (George et al., 2013, 2016; Nidheesh et al., 2014a), commercial graphite-felt (Khataee et al., 2009; Panizza and Oturan, 2011) and chemically or electrochemically modified graphite felt (Zhou et al., 2013; 2014), carbon sponge (Özcan et al., 2008c) etc. were used as the cathode material for the efficient electrogeneration of hydrogen peroxide in EF cell. Özcan et al. (2008c) compared the dye 
degradation efficiency of carbon sponge and carbon-felt for the abatement of acidified basic blue 3 solutions and found that carbon sponge is the effective cathode than carbon felt for EF process. By analyzing the reported literatures, various forms of Pt have been used frequently as anode in EF cell for the degradation of various organic pollutants (Nidheesh and Gandhimathi, 2012; Sopaj et al., 2015, 2016).

The efficiency of EF process increases by combining AO and EF processes. This can be achieved by the use of an $\mathrm{O}_{2}$ overvoltage anode in the EF process along with the carbonaceous cathode. Oturan et al. (2012) showed that this process was able to mineralize quasi-completely the herbicide atrazine and its by-product cyanuric acid which already reported many times to be recalcitrant to hydroxyl radicals.

EF process has been proved as an efficient tool for the abatement of dyes from water medium. Nidheesh and Gandhimathi (2014a) used graphite-graphite electrolytic system for the abatement of rhodamine $\mathrm{B}(\mathrm{RhB})$ at $\mathrm{pH} 3$. The authors reported that with the increase in electrode immersion depth the efficiency of the electrolytic system also increases. This is mainly due to the increased contact between cathode surface and air bubbles and the authors recommended to use bubble column reactor with lengthy electrode for the efficient removal of organic pollutants. Similarly, complete destruction of azure B and 95\% TOC abatement at the end of $8 \mathrm{~h}$ EF treatment was observed by Olvera-Vargas et al. (2014). Almomani and Baranova (2013) analyzed the dye removal efficiencies of single and two compartment cells in the presence of stainless steel cathode and BDD anode and observed that two compartment cell is better than single cell for the removal of dyes from aqueous medium. Lahkimi et al. 403 (2007) investigated the depollution of methylene blue, Congo red and yellow drimaren using 404 carbon felt cathode and Pt sheet anode and observed a rapid degradation of dyes in their single and mixture solution. Almost complete mineralization of dyes also observed by 
caused by alizarin red (Panizza and Oturan, 2011) and acid red 97 (Kayan et al., 2010) was removed effectively using the graphite-felt and carbon-felt cathodes, respectively. Diagne et al. (2014) compared the efficiencies of AO and EF processes for the removal of indigo dye and observed higher mineralization efficiency for EF process. Complete mineralization of the dye was observed within $2 \mathrm{~h}$ of electrolysis. Yu et al. (2015) modified graphite felt by using carbon black and PTFE; and observed 10.7 times higher $\mathrm{H}_{2} \mathrm{O}_{2}$ production compared to unmodified electrode. EF process using this modified graphite felt cathode is efficient for complete removal of $50 \mathrm{mg} \mathrm{L}^{-1}$ methyl orange within $15 \mathrm{~min}$ and $95.7 \%$ TOC removal at $2 \mathrm{~h}$ electrolysis; this efficiencies being more than 4 times that of EF process operated with raw graphite felt cathode.

Apart from, solution $\mathrm{pH}$, catalyst dosage, initial pollutant concentration, electrode area, applied current and inner electrode spacing; the hardness in the water also affects the efficiency of EF process significantly (dos Santos et al., 2016). The presence of magnesium and calcium in water medium reduced the dye removal efficiency of EF process for the dye ericochrome black T. This reduction in the performance of EF process is mainly related to the difficulty to break the divalent cation- ericochrome black T complex by ${ }^{\bullet} \mathrm{OH}$.

$\mathrm{Xu}$ et al. (2014) prepared graphene doped gas diffusion electrode using modified Hummers' method and used for the removal of reactive brilliant blue in a three electrode undivided cell of volume $200 \mathrm{~mL}$. The study concluded that under the optimal conditions, $80 \%$ of the dye and $33 \%$ of TOC were removed after $180 \mathrm{~min}$ of electrolysis by the novel electrode. Ghoneim et al. (2011) observed a complete dye removal and 97\% of mineralization by $\mathrm{EF}$ process in an electrolytic cell of $600 \mathrm{~mL}$ capacity containing reticulated vitreous carbon cathode, platinum gauze anode and $0.2 \mathrm{mM}$ sunset yellow FCF azo dye. Sirés et al. (2008) compared the dye removal efficiency of EF cell with carbon-felt cathode for the degradation of crystal violet (CV), fast green FCF (FCF), methyl green (MeG) and malachite 
green (MG). In this study, it was observed that the absolute rate constant for their reaction with hydroxyl radicals increases in the order $\mathrm{MeG}<\mathrm{FCF}<\mathrm{CV}<\mathrm{MG}$. Total depollution of a dye mixture containing the above four dyes with a COD of $1000 \mathrm{mg} \mathrm{L}^{-1}$ was also observed. Complete decolorization and approximately $85-90 \%$ mineralization of levafix red CA and levafix blue CA was observed by El-Desoky et al. (2010). Similar results were obtained in the cases of real dyeing wastewater (Wang et al., 2010), reactive blue 4 (Gözmen et al., 2009), direct orange 61 (Hammami et al., 2007), etc. reported that dye removal rate in cathodic compartment was much faster than that in anodic compartment. Scialdone et al. (2013) performed the abatement of acid orange 7 in a microfluidic reactor and reported that the process is efficient for the usage of cheaper and easier to handle graphite as cathodic material, mainly due to the sufficient oxygen production from the anode. Therefore, external addition of air or oxygen is not required for this type of reactor. Iglesias et al. (2013a) used airlift continuous reactor for the removal of reactive black 5 and lissamine green B and accomplished high decolorization percentages at high residence times. Methyl orange removal in a $3 \mathrm{~L}$ capacity pilot flow plant was studied by IsarainChávez et al. (2013) and obtained $80 \%$ of decolorization efficiency at the optimal conditions. Nanostructured $\mathrm{ZnO}-\mathrm{TiO}_{2}$ thin films deposited on graphite felt anode (El-Kacemi et al., 2016) exhibited higher dye removal and mineralization efficiency. Within $60 \mathrm{~min}$ of electrolysis Amido black 10B dye was discolored and the mineralization efficiency of the EF process reached $91 \%$ after $6 \mathrm{~h}$ of electrolysis. Application of graphene based electrode material improves the efficiency of EF process in a noticeable manner (Yang et al., 2017). 
electrochemically exfoliated graphene (Yang et al., 2017) electrodes exhibited excellent hydrogen peroxide generation potential and subsequent dye removal efficiency. radical (Oturan and Aaron, 2014). Apart from this, other forms iron like zero-valent iron $\left(\mathrm{Fe}^{0}\right)$ and ferric ions $\left(\mathrm{Fe}^{3+}\right)$ can be used as Fenton catalyst. Addition of $\mathrm{Fe}^{3+}$ instead of $\mathrm{Fe}^{2+}$ undergoes the ferrous ion regeneration reaction prior to Fenton reaction. $\mathrm{Fe}^{0}$ addition leads to the production of $\mathrm{Fe}^{2+}$ by the reaction between hydrogen peroxide as in Eq. (22) (Fu et al. 2010a). Oturan et al. (2008a) used ferric ion instead of ferrous ion for the degradation of malachite green in $\mathrm{Pt} / \mathrm{CF}$ cell at $\mathrm{pH}$ 3. The authors observed a total decolorization within 22 min and total mineralization within 540 min of electrolysis at an applied current of $200 \mathrm{~mA}$. Özcan et al. (2009b) investigated the acid orange 7 removal by EF process using ferric ions and $92 \%$ of TOC removal was reported. Nidheesh and Gandhimathi (2014b) compared the $\mathrm{RhB}$ ) removal efficiencies of $\mathrm{Fe}^{0}, \mathrm{Fe}^{2+}$ and $\mathrm{Fe}^{3+}$ in graphite-graphite $\mathrm{EF}$ system. The rate of dye removal at the optimal conditions follows the order of $\mathrm{Fe}^{0}>\mathrm{Fe}^{3+}>\mathrm{Fe}^{2+}$. But the optimum amount of Fenton's reagent followed the order of $\mathrm{Fe}^{0} \sim \mathrm{Fe}^{2+}>\mathrm{Fe}^{3+}$.

$$
\mathrm{Fe}^{0}+\mathrm{H}_{2} \mathrm{O}_{2} \rightarrow \mathrm{Fe}^{2+}+2 \mathrm{OH}^{-}
$$

Persistent organic pollutant abatement using EF like process also received a great attention in recent years. The transition metals having more than one oxidation states and having a difference of unity in oxidation states can undergo Fenton like reactions as shown in Eq. (23). Various transition metals like Mn (Balci et al., 2009; George et al., 2014; Nidheesh and Gandhimathi, 2014b), Cu (Oturan et al., 2010b; George et al., 2013b;Nidheesh and Gandhimathi, 2014b), Co (Oturan et al., 2010b), Ag (Oturan et al., 2010b), Ni (George et al., 2014) etc. have been used as EF like catalyst for the abatement of various pollutants.

$$
\mathrm{M}^{(\mathrm{n}-1)}+\mathrm{H}_{2} \mathrm{O}_{2} \rightarrow \mathrm{M}^{\mathrm{n}+}+\mathrm{HO}^{\bullet}+\mathrm{OH}^{-}
$$


Recently, the EF related researches focused on the heterogeneous EF system (Nidheesh,

2015). In this process, solid catalysts containing iron species are used as the iron source instead of ferrous salts. Heterogeneous catalyst can be reused several times for the degradation of organic pollutants. Recently Oturan and co-workers proposed EF-pyrite process and found it to be very efficient for the mineralization of various organic pollutants (Amar et al., 2015; Barhoumi et al., 2015; 2016). Labiadh et al. (2015) used this technology for the removal of 4-amino-3-hydroxy-2-p-tolylazo-naphthalene-1-sulfonic acid, an azo dye from water medium and found complete mineralization of $175 \mathrm{mg} \mathrm{L}^{-1}$ dye within $8 \mathrm{~h}$ of electrolysis. Nidheesh et al. (2014a) prepared magnetite by the chemical precipitation method and used for the decolorization of RhB. The authors used magnetite containing various concentrations of ferrous and ferric ions and found that the magnetite with $\mathrm{Fe}(\mathrm{II}) / \mathrm{Fe}(\mathrm{III})$ ratio 2:1 and 1:2 has good dye removal efficiency than other catalysts. At the optimal conditions, $97 \%$ of RhB was removed effectively by the heterogeneous EF process. Similarly EF oxidation of acid red $3 \mathrm{R}$ in the presence of $\mathrm{Fe}_{2} \mathrm{O}_{3} / \gamma-\mathrm{Al}_{2} \mathrm{O}_{3}$ was investigated by Yue et al. (2014) and it was reported $77 \%$ dye removal within 100 min of electrolysis. Rosales et al. (2012) used Fe alginate gel beads for the removal of azure B and lissamine green B; and obtained almost complete removal of dyes from aqueous solution. Iglesias et al. (2013a) used the same catalyst for the decolorization of reactive black and lissamine green B 5 in an airlift continuous reactor. Iron loaded sepiolite was used as a heterogeneous EF catalyst for the removal of reactive black 5 in a continuous flow mode of operation (Iglesias et al., 2013b) and obtained 80 to $100 \%$ dye removal at the optimal conditions. Liang et al. (2016) investigated the effect of five metals $(\mathrm{Cu}, \mathrm{Ce}, \mathrm{Mn}, \mathrm{Fe}$ and $\mathrm{Co})$ and their loading contents on methyl orange degradation, observing the highest activity on Co/GDE and good stability toward wide $\mathrm{pH}$ ranges (3-9). 

species from the heterogeneous catalyst are released into the solution and reacts with the hydrogen peroxide produced at the cathode surface as in conventional Fenton process. In some of the cases, the Fenton reactions may occurs at the solid catalyst surface, without the dissolution of iron species. At these conditions the catalyst should be in suspension or efficient mixing should be there for the effective removal of organic pollutants.
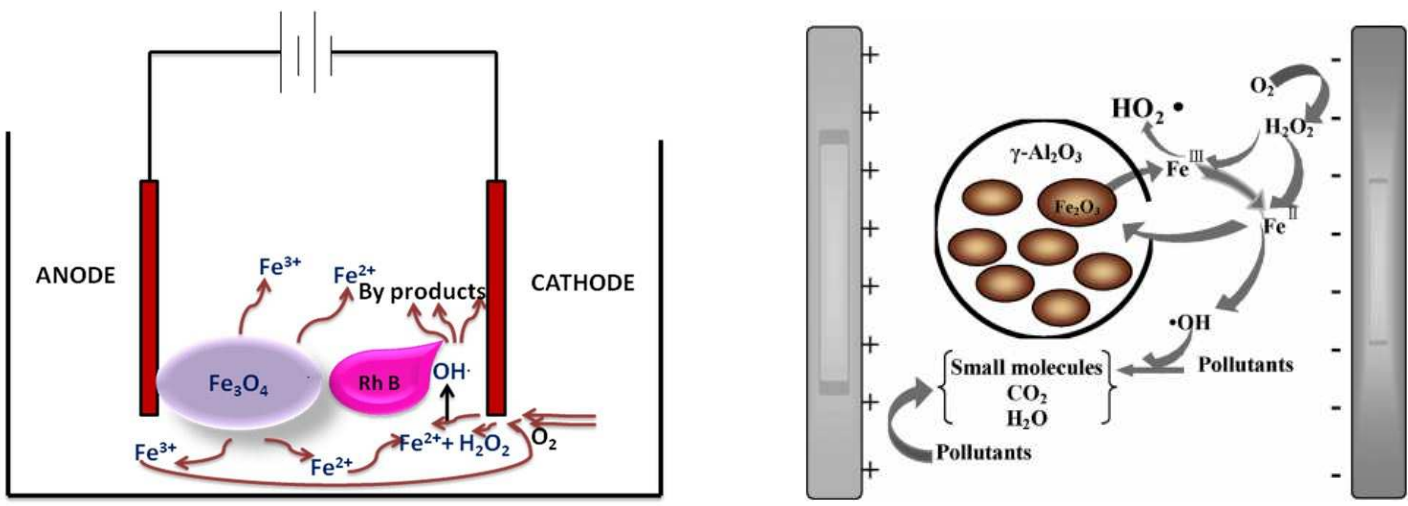

Fig. 2 Dye removal mechanism of heterogeneous EF process using (a) magnetite (Nidheesh et al., 2014d), (b) $\mathrm{Fe}_{2} \mathrm{O}_{3} / \gamma-\mathrm{Al}_{2} \mathrm{O}_{3}$ (Yue et al., 2014). Reprinted with permission from $R S C A d v$., Copyright 2014 RSC and J. Ind. Eng. Chem., Copyright The Korean Society of Industrial and Engineering Chemistry and Elsevier 2013, respectively. cells for the abatement of persistent organic pollutants. 3D EF process is similar to the conventional two electrode system. But it contains particle electrode as the third electrode. Particle electrode is generally a granular material, which may contain iron oxides and filled between anode and cathode. Iron loaded inert substances and iron oxides can be used as the particle electrode for the EF system. Polarization of the particle electrode occurs during the electrolysis. Due to the polarization, these particles converts as a large numbers of charged microelectrodes with anode in one surface and cathode in other surface (Zhang et al., 2013). 
522 These electrodes reduce the pollutant concentration by the sorption process, increasing the 523 ionic strength of the electrolytic cell and supplying additional iron species in the system. In 524 EF process, the particle electrodes predominately act as a heterogeneous EF catalyst (Wang et 525 al., 2014a). Thus the efficiency of 3D EF system is higher than conventional EF system due 526 to its large electrode surface and higher mass transfer (Wang et al., 2008a). The COD removal efficiency of $3 \mathrm{D}$ system should be $10-15 \%$ higher than that of conventional $\mathrm{EF}$ system (Zhang et al., 2013). heterogeneous Fenton catalyst in 3D EF system for the removal of methyl orange (MO). 20$30 \%$ of methyl orange mineralization efficiency increment was observed with the addition of the heterogeneous Fenton catalyst. More than $80 \%$ of dye removal efficiency after 10 min of electrolysis and $40 \%$ of TOC after $2 \mathrm{~h}$ of electrolysis were observed. Based on the system as in Fig. 3.

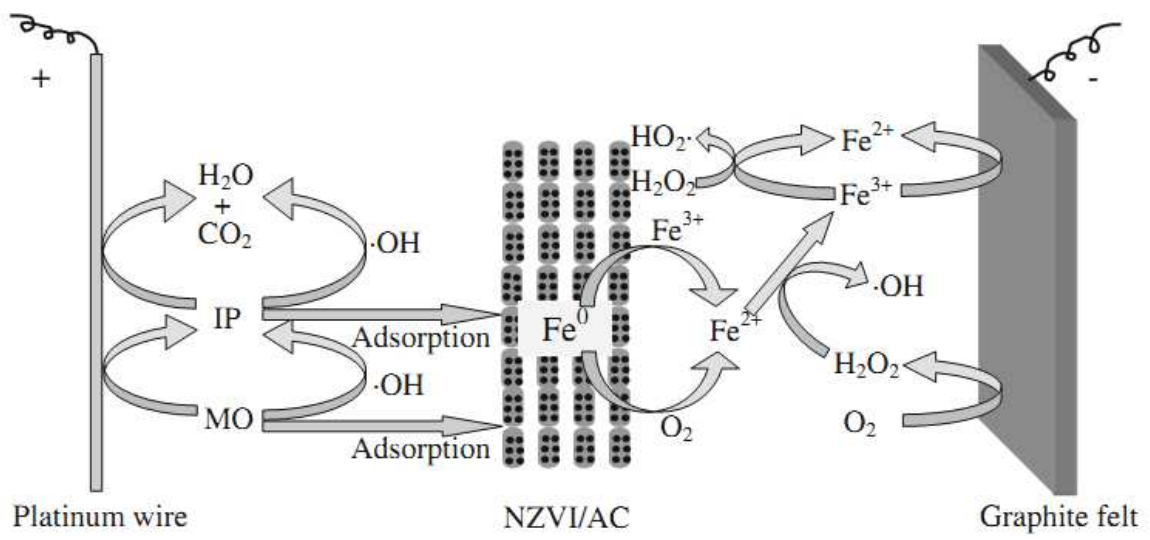

Fig. 3 Methyl orange degradation mechanism in a 3D EF system (where, MO is methyl orange, NZVI/AC is nanoscale zero-valent iron/activated carbon and IP is intermediate products). Reprinted from Zhang et al. (2014), Copyright 2014, Springer-Verlag Berlin 

manganese loaded on the particle electrodes by ultrasound impregnation calcinations approach for the removal of $\mathrm{RhB}$ from aqueous solution by 3D EF process containing $\mathrm{Pt}$ anode and stainless steel cathode. The authors observed a complete removal of dye within 50 min of electrolysis. Electrolysis of real dyeing wastewater in the presence of graphite raschig rings particle electrode, Pt/Ti plate anode and graphite cathode was carried out by Wang et al. (2008a). The authors attained a 70.6\% color removal under specific operation conditions in 150 min. Wang et al. (2014a) used particle electrode prepared from steel slag for the removal of $\mathrm{RhB}$ and obtained $82.4 \%$ and $65.45 \%$ of $\mathrm{RhB}$ removal with and without of air supply within 60 min of electrolysis.

Removal of dyes from water medium using EF process under continuous flow mode was tested by Nidheesh and Gandhimathi (2015a, b). The authors used bubble column reactor (BCR) of capacity $3 \mathrm{~L}$ for the removal of $\mathrm{RhB}$ from aqueous solution. They studied the effects of applied voltage, solution $\mathrm{pH}$, catalyst concentration and inlet flow rate on the removal of dyes in continuous flow mode. At the optimal conditions, $98 \%$ of the RhB solution having an initial concentration of $50 \mathrm{mg} \mathrm{L}^{-1}$ was removed effectively using the BCR under continuous flow mode. Similarly, EF process operated in BCR is highly efficient for the treatment of real textile wastewater (Nidheesh and Gandhimathi, 2015b). Due to the increased mass and electron transfer, flow-through EF reactor (in which solution is flow through anode and cathode) was found more energy-efficient and more pollutant removal efficiency than conventional EF reactor (Ma et al., 2016; Ren et al., 2016).

Even EF or related processes are very efficient for the abatement of various persistent organic pollutants from water medium; the incomplete mineralization of these pollutants may cause further environmental pollution. Some of the intermediate compounds are more toxic than their parent compounds. For example, Le et al. (2016) carried out the toxicity analysis 
566 during the acid orange 7 degradation via EF process. In the initial periods of electrolysis, the

567 toxicity values increased abruptly and are very much higher than that of acid orange 7 . This is

568 mainly due to the generation of more toxic intermediate products such as 1,2-naphthaquinone

569 and 1,4-benzoquinone. The subsequent degradation of these compounds resulted in the

570 production of carboxylic acids and decreased the toxicity values significantly. But,

571 phytotoxicity and microbial toxicity of real textile wastewater has been reduced significantly

572 after $1 \mathrm{~h}$ EF treatment (Roshini et al., 2017).

\subsection{Peroxi-coagulation}

Peroxi-coagulation is a modified EF process which use iron or stainless steel as anode

576 for supplying ferrous ions in water medium, instead of external ferrous ion addition as in EF

577 process. Ferrous ions continuously generated from anode by oxidation of a sacrificial anode according to Eq. (24). In the case of use an appropriate cathode able to generate $\mathrm{H}_{2} \mathrm{O}_{2}$ and $\mathrm{O}_{2}$ supply, Fenton's reaction takes place to form ${ }^{\circ} \mathrm{OH}$. With the increase in electrolysis time, ferric ions accumulates in the aqueous medium leads to the formation of $\mathrm{Fe}(\mathrm{OH})_{3}$ precipitate. Thus, peroxi-coagulation process is a combination of EF and electrocoagulation, in which organic pollutants are removed by the attack of hydroxyl radicals (degradation process) and coagulation with iron precipitates (Brillas and Casado, 2002). This process was firstly applied for the removal of aniline from aqueous medium (Brillas et al., 1997). The overall reactions occurring in a peroxi-coagulation cell along with organic pollutants removal mechanism are shown in Fig. 4.

$$
\mathrm{Fe} \rightarrow \mathrm{Fe}^{2+}+2 \mathrm{e}^{-}
$$




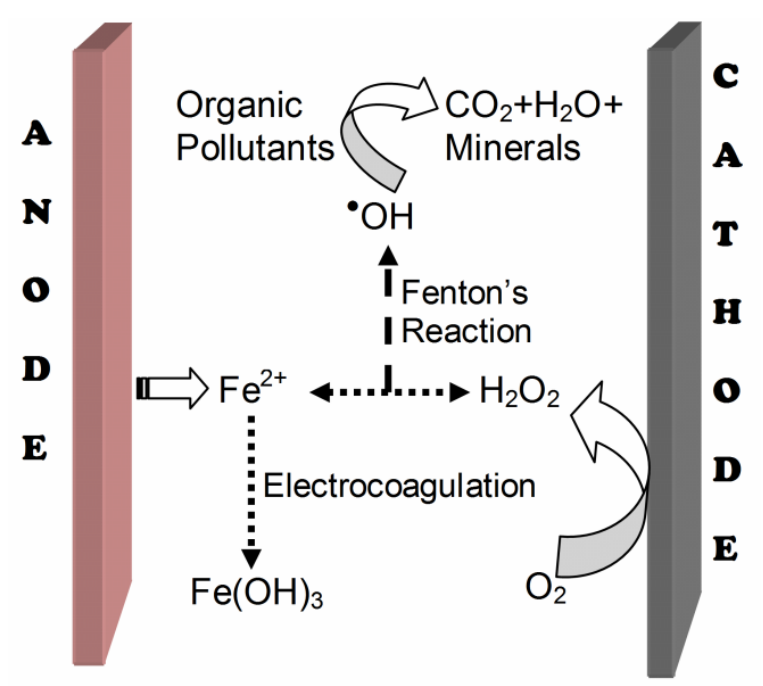

Fig. 4 Working principles of peroxi-coagulation process

Increase in solution $\mathrm{pH}$ with electrolysis time is the difference in peroxi-coagulation with EF process (Venu et al., 2014, 2016). Hydrogen evolution reaction by the water reduction at the cathode surface (Eq. (25)) is the main reason behind the raise in solution pH (Drogui et al., 2008). This increase in $\mathrm{pH}$ increases also the rate $\mathrm{Fe}(\mathrm{OH})_{3}$ formation and causes electrocoagulative removal of pollutants along with oxidative action Fenton's reaction. This results in a higher amount of sludge production in the electrolytic cell. Brillas and Casado (2002) observed higher pollutant removal efficiency for peroxi-coagulation than EF process for currents $\geq 10$ A and this is mainly attributed to the effective removal of intermediate compounds formed (by the attack of hydroxyl radicals) and by coagulation (adsorption or imprisonment in $\mathrm{Fe}(\mathrm{OH})_{3}$ ). The sludge formation in the peroxi-coagulation cell can be reduced by maintaining the solution $\mathrm{pH}$ to 3 . At these conditions, the iron (III) concentration in the system is less than that of ferrous or ferric ions, results in Fenton's reaction to take place more efficiently.

$$
2 \mathrm{H}_{2} \mathrm{O}+2 \mathrm{e}^{-} \Leftrightarrow \mathrm{H}_{2}+2 \mathrm{OH}^{-}
$$

A few studies have been reported for the dye removal by peroxi-coagulation process. Zarei et al. (2010a) used peroxi-coagulation process for the removal of four dyes namely C.I. 
basic red 46, C.I. basic blue 3, C.I. basic yellow 2 and malachite green from aqueous solution at $\mathrm{pH} 3$ and reported about $90 \%$ of dye removal within 10 min electrolysis. Salari et al. (2009) reported that peroxi-coagulation process has the ability to decolorize $90 \%$ of the dye in less than $30 \mathrm{~min}$ and $81 \%$ mineralization of dye at $6 \mathrm{~h}$. Similar results were reported by Zarei et al. (2009).

Sludge formation in peroxi-coagulation process can be reduced by regulating the solution $\mathrm{pH}$ to 3 . Nidheesh and Gandhimathi (2014 d) reported that $\mathrm{pH}$ regulated peroxicoagulation has higher dye removal efficiency than that of $\mathrm{pH}$ unregulated peroxi-coagulation process. But the authors observed scavenging effects by the addition of sodium salts containing chloride, bicarbonate, carbonate and sulphate. For maintaining the $\mathrm{pH}$, the authors used sulphuric acid and regulated the solution $\mathrm{pH}$ to 3 at every $15 \mathrm{~min}$ interval. This increased the concentration of sulphate ions in the cell. By the addition of sodium salts, higher amount of sulphate salts precipitate produces (as per common ion effect according to Le Chatelier's principle) and form a layer at the cathode surface. The authors observed a white layer formation on the cathode surface after the electrolysis, and this layer contains higher amount of sodium sulphates. This layer was removed with the insertion of cathode in an acid solution. Due to this layer formation, the volume of active pores at cathode surface reduces and results in lesser hydrogen peroxide formation. This causes a reduction in dye removal efficiency by the addition of sodium salts.

Nidheesh and Gandhimathi (2014c) compared the decolorization and degradation efficiencies of $\mathrm{EF}$, peroxi-coagulation $(\mathrm{PC})$ and $\mathrm{pH}$-regulated peroxi-coagulation (PC-pH) processes from real textile wastewater. Based on the experimental results, the authors concluded that the color and COD removal efficiency of EF process is mainly by the oxidation of pollutants and the efficiency of peroxi-coagulation is mainly by the combination 630 of oxidation and separation processes. The authors observed a higher sludge production for 
631 PC and PC-pH processes at higher $\mathrm{pH}$ values and concluded that the higher removal 632 efficiencies at higher $\mathrm{pH}$ values is mainly by electrocoagulation process. The sludge

633 produced from PC process was reused as a heterogeneous EF catalyst for the abatement of 634 same real textile wastewater and observed $97 \%$ of color, $47 \%$ of COD and $33.2 \%$ TOC 635 reductions.

\subsection{Fered-Fenton and Anodic Fenton processes}

Fered-Fenton process is a modified form of Fenton process, in which hydrogen peroxide and ferrous ions are added externally to the electrolytic cell and then ferrous iron

640 regenerated electrochemically from reduction of $\mathrm{Fe}^{3+}$ formed in Fenton's reaction (Eq. 15) for 641 the improvement of process efficiency (Brillas et al., 2009). This process is also known as 642 EF-Fere and is suitable for the abatement of organic pollutants with high TOC value and 643 lower biodegradability. With the addition of hydrogen peroxide and ferrous iron salt, conventional Fenton's reaction occurs between ferrous ion and hydrogen peroxide and ${ }^{\circ} \mathrm{OH}$ produced following Fenton's reaction (Eq. 15) results in the reduction of organic loading. Further reduction of organic pollutant can be attributed to conventional Fenton process assisted by electrochemistry since Fenton's reaction is catalyzed by the regeneration of ferrous ions from the electrochemical reduction of ferric ions (Brillas et al., 2009).

Anodic Fenton process is a Fenton related electrochemical peroxidation process. It can 650 be considered as a modified form of peroxi-coagulation process. One of the major 651 disadvantages of peroxi-coagulation process is the sludge production due to the formation of $652 \mathrm{Fe}(\mathrm{OH})_{3}$ in excess of iron(III) in the solution. The main problem for this is the lack of 653 sufficient quantity of hydrogen peroxide production at the cathode surface (As per 654 conventional Fenton's reaction, the theoretical ratio of ferrous to hydrogen peroxide is 1 . But 
in peroxi-coagulation process, the concentration of ferrous ion increases and that of hydrogen peroxide comes to saturation or decreases with electrolysis time). This results in higher sludge formation and may cause scavenging reactions as given below (Brillas et al., 2009).

$$
\begin{aligned}
& \mathrm{Fe}^{2+}+\mathrm{HO}^{\bullet} \rightarrow \mathrm{Fe}^{3+}+\mathrm{HO}^{-} \\
& \mathrm{Fe}^{3+}+\mathrm{H}_{2} \mathrm{O}_{2} \rightarrow \mathrm{FeO}_{2} \mathrm{H}^{2+}+\mathrm{H}^{+} \leftrightarrow \mathrm{HO}_{2}^{\cdot}+\mathrm{Fe}^{2+}+\mathrm{H}^{+}
\end{aligned}
$$

660 This can be reduced by the external addition of hydrogen peroxide, known as anodic Fenton process. Ghosh et al. (2012) studied the degradation of methylene blue and titan yellow dye solutions using this method (but authors mentioned it wrongly as EF process) and observed $98 \%$ and $96 \%$ respective dyes removal after $60 \mathrm{~min}$ of electrolysis at $\mathrm{pH} 3,1 \mathrm{mM}$ of $\mathrm{H}_{2} \mathrm{O}_{2}$ and current density of $4.31 \mathrm{~mA} \mathrm{~cm}^{-2}$. Eslami et al. (2013) compared the efficiencies of anodic Fenton process (but authors mentioned it wrongly as EF process) with conventional Fenton process for the removal of color and COD from real textile wastewater and higher removal efficiency for anodic Fenton process was observed. The decolorization and COD removal efficiencies of anodic Fenton process after 60 min of electrolysis were found as $72.9 \%$ and $70.6 \%$, respectively, within $350 \mathrm{~mA}$ current and externally added $1978 \mathrm{mg} \mathrm{L} \mathrm{L}^{-1} \mathrm{H}_{2} \mathrm{O}_{2}$ concentration. At the same time, $52.3 \%$ of color and $51.2 \%$ of COD were removed via Fenton process after 120 min of treatment at $1978 \mathrm{mg} \mathrm{L}^{-1} \mathrm{H}_{2} \mathrm{O}_{2}$ concentration and $250 \mathrm{mg} \mathrm{L}^{-1}$ of ferrous ion concentration. effect of hydroxyl ions produced by the water reduction at cathode, Saltmiras and Lemley (2000) used divided electrolytic cell. Anode cell and cathode cell are connected with a salt bridge. Then the anode cell is enriched with the electrolytically generated ferrous ions and Fenton reactions occur with the external addition of hydrogen peroxide. Thus, anodic Fenton process reduces the external addition of large quantity of iron salts as in conventional Fenton 
679 process and the effluent $\mathrm{pH}$ can be partially neutralized by combining the treated solutions 680 from each cells (Wang and Lemley, 2002). But the scale up of anodic Fenton with a salt 681 bridge is a little difficult task because the salt bridge requires frequent replacement of the 682 saturated $\mathrm{NaCl}$ solution (Wang and Lemley, 2003). To overcome this, Lemley group 683 developed membrane anodic Fenton process, in which an ion exchange membrane used 684 between anode cell and cathode cell, instead of salt bridge.

\subsection{Photoelectro-Fenton process}

A combination of UV radiation along with EF process, known as photoelectro-Fenton

688

690

691

692

693

(PEF) process, produces more hydroxyl radicals than that in conventional EF process. This enhances the rate of dye degradation by the Fenton's reaction. The additional hydroxyl radicals are produced by the photochemical reduction of $\mathrm{Fe}^{3+}$ ions from $\mathrm{UV}$ light irradiation as in Eq. 28 (Brillas et al., 1998 a, b; Muruganandham and Swaminathan, 2004). On the other hand the regeneration of $\mathrm{Fe}^{2+}$ ions by this reaction (Eq. (28)) catalyzes also the Fenton's reaction (Eq. 15) to produce more ${ }^{\circ} \mathrm{OH}$. The photolysis of in situ produced $\mathrm{H}_{2} \mathrm{O}_{2}$ in the presence of UV light also produces additional ${ }^{\circ} \mathrm{OH}$ according to Eq. (29) (Brillas, 2014), but the amount of ${ }^{\circ} \mathrm{OH}$ produced by this reaction is not significant because of very low absorption coefficient of $\mathrm{H}_{2} \mathrm{O}_{2}$.

$$
\begin{aligned}
& \mathrm{Fe}^{3+}+\mathrm{H}_{2} \mathrm{O}+\mathrm{h} v \rightarrow \mathrm{HO}^{\bullet}+\mathrm{Fe}^{2+}+\mathrm{H}^{+} \\
& \mathrm{H}_{2} \mathrm{O}_{2}+\mathrm{h} v \rightarrow 2 \mathrm{HO}^{\bullet}
\end{aligned}
$$

Production of hydroxyl radicals and regeneration of ferrous ions from the photodegradation of iron complexes and ferric carboxylates is another advantage of PEF over conventional EF process. The photo-reduction of ferric hydroxyl complexes especially $\mathrm{Fe}(\mathrm{OH})^{2+}$ produces additional ${ }^{\circ} \mathrm{OH}$ as in Eq. 30 (Gogate and Pandit, 2004; Kavitha and Palanivelu, 2004; Brillas 
2014). Similarly, photo-reactive ferric carboxylates also undergoes degradation process and produces additional ferrous ions and ${ }^{\circ} \mathrm{OH}$ according to Eq. (31) (Brillas, 2014).

Many researchers put an interest on dye removal using PEF process. Khataee et al. (2014) compared the efficiency of EF and PEF processes for the abatement of C.I. Acid Blue 5 under recirculation mode with a cathode containing multi walled carbon nanotubes. The authors observed dye removals of $98 \%$ after 60 min of electrolysis for PEF processes. Similarly, Bedolla-Guzman et al. (2016) compared the efficiencies of anodic oxidation, EF and PEF processes for the degradation of Reactive Yellow 160 dye, using BDD anode. The authors observed dye removal efficiency order as: $\mathrm{PEF}>\mathrm{EF}>$ anodic oxidation. Similar results are reported by Solano et al. (2015) for the degradation of Congo red dye and El-Ghenymy et al. (2015) for the abatement of malachite green oxalate dye. Khataee et al. (2010a) used carbon nanotube-polytetrafluoroethylene cathode for the removal of C.I. basic red 46 by the oxalate catalyzed PEF process and compared its efficiency with the efficiencies of EF and PEF processes. The authors reported that oxalate catalyzed PEF process has higher dye removal efficiency than that of PEF and EF process. Abatement of $244 \mathrm{mg} \mathrm{L}^{-1}$ Acid Red 29 by PEF process using BDD anode and carbon-PTFE cathode in an undivided cell was studied by Almeida et al. (2012) and observed an almost complete dye mineralization. Garcia-Segura et al. (2012) compared the Direct Yellow 4 degradation efficiencies of EF, PEF and photoassisted EF process. Photo-assisted EF was performed by applying EF treatment for a particular time, followed by the photolysis of treated dye solution. They reported higher dye removal efficiency for PEF process (almost total mineralization). The authors also observed an equivalent dye removal capacity of PEF process for photo-assisted EF process after giving sufficient time for the EF process to produce intermediates that can be mineralized by the photolysis. Peralta-Hernández et al. (2008) compared the Orange II removal efficiencies of direct photolysis, EF and PEF processes and observed $31 \%, 63 \%$ and $83 \%$ of TOC removals, 
respectively. Mineralization of Acid Red 14 by PEF process using an activated carbon fiber cathode was examined by Wang et al. (2008b) and compared its efficiency with EF process. The authors observed $60-70 \%$ mineralization efficiency for EF process and more than $94 \%$ mineralization efficiency for PEF process. Mineralization and decolorization of aqueous solution containing Acid Violet 7 and Reactive Black 5 by EF and PEF processes using a vitreous carbon electrode cathode was studied by Salazar and Ureta-Zañartu (2012) and observed more than $90 \%$ mineralization efficiency for PEF process.

The pseudo first order rate of dye removal by PEF process was modeled as a function of catalyst concentration, initial dye concentration, solution $\mathrm{pH}$, applied current and flow rate by Khataee et al. (2014). The authors reported the rate constant as:

$$
k_{\text {app }}=1310.4 \frac{[\mathrm{CA}]^{0.48} \mathrm{I}^{0.55}}{[\mathrm{Dye}]^{1.07} \mathrm{pH}^{1.75} \mathrm{Q}^{0.84}}
$$

where, $k_{\text {app }}$ is the apparent rate constant following first order kinetic, CA is the catalyst concentration in $\mathrm{mM}, I$ is the applied current in $\mathrm{A}, \mathrm{Q}$ is the flow rate in $\mathrm{L} \mathrm{h}^{-1}$.

Coupling of conventional photocatalysis with PEF process received great attention in recent years. The principles of photocatalysis were explained well by various researchers (Bahnemann, 2004; Girish Kumar and Gomathi Devi, 2011; Rauf et al., 2011; Lam et al., 2012). Iranifam et al. (2011) used $\mathrm{ZnO}$ nanoparticles as the photo catalyst for the removal of C.I. Basic Yellow 28 from aqueous solution and compared the dye removal efficiencies of ultraviolet-C (UV-C), EF, UV/ZnO, PEF and PEF/ZnO processes. The authors found the decreasing color removal efficiency order as: $\mathrm{PEF} / \mathrm{ZnO}>\mathrm{PEF}>\mathrm{UV} / \mathrm{ZnO}>\mathrm{EF}>\mathrm{UV}-\mathrm{C}$. Similarly, Khataee and Zarei (2011) reported the C.I. Direct Yellow 12 removal efficiency order as: $\mathrm{PEF} / \mathrm{ZnO}>\mathrm{PEF}>\mathrm{EF}>\mathrm{UV} / \mathrm{ZnO}$. Photocatalytic treatment of C.I. Acid Red 17 using immobilized $\mathrm{TiO}_{2}$ nanoparticles combined with PEF process was investigated by Khataee et al. (2010b) and it was observed the color removal decreasing order as: $\mathrm{PEF} / \mathrm{UV} / \mathrm{TiO}_{2}>\mathrm{PEF}>$ 
$752 \mathrm{EF}>\mathrm{UV} / \mathrm{TiO}_{2}$. The authors observed $93.7 \%, 85.9 \%, 66.8 \%$ and $20 \%$ decolorization 753 efficiencies for $\mathrm{PEF} / \mathrm{UV} / \mathrm{TiO}_{2}, \mathrm{PEF}, \mathrm{EF}$ and $\mathrm{UV} / \mathrm{TiO}_{2}$ processes respectively. Similar order 754 was reported by Zarei et al. (2010b) for the removal of C.I. Basic Red 46. The authors 755 observed $98.8 \%$ mineralization of $20 \mathrm{mg} \mathrm{L}^{-1}$ C.I. Basic Red 46 dye at $6 \mathrm{~h}$ of electrolysis using $756 \mathrm{PEF} / \mathrm{TiO}_{2}$ process.

\subsection{Solar Photoelectro-Fenton}

PEF process has been found as an effective tool for the abatement of dyes from water medium. But the higher energy consumption of artificial UV light used in PEF process increases the operational cost of this process (Brillas, 2014). In order to solve this disadvantage of PEF process and to increase the chance of applying this process in the real field, Brillas' group (Flox et al., 2007a, 2007b) proposed a modified form of PEF process, known as solar photoelectro-Fenton (SPEF) process for the degradation and removal of various organic persistent pollutants. In this process, the EF treated wastewater is irradiated with sunlight $(\lambda>300 \mathrm{~nm})$, instead of artificial UV light as in PEF process. Therefore, SPEF method is cheap, uses renewable energy source, high energy efficient, amenable to automation, versatile and safe (Martínez-Huitle and Brillas, 2009; Brillas, 2014). It is also found that the efficiency of SPEF is higher than that of PEF process due to the greater intensity of UVA and UVB lights of sunlight which can photolyze the ferric carboxylate complexes more rapidly (Garcia-Segura et al., 2013; Brillas, 2014). Also, compared to EF process, SPEF process is more potent than EF, with higher mineralization efficiency, higher current efficiency and lower energy consumption (Salazar et al., 2011). Garcia-Segura and Brillas (2016) compared the performance of SPEF for the degradation of monoazo, diazo and triazo dyes in water medium. Acid Orange 7, Acid Red 151 and Disperse Blue 71 were considered as the model monoazo, diazo and triazo dyes, respectively. SPEF process is very 
much efficient for the degradation of monoazo dye with almost complete mineralization after $3 \mathrm{~h}$ of electrolysis. At the same time, the dye degradation efficiency of SPEF is high for triazo dye than diazo dye.

Ruiz et al. (2011a) used 2.5 L flow plant for the degradation of Acid Red and Acid Yellow from water medium. The electrolytic cell was equipped with carbon-PTFE cathode and BDD anode. The solar photo-reactor having irradiated volume of $600 \mathrm{~mL}$ and containing mirror at bottom with a horizontal inclination of $30^{\circ}$. The authors observed a rapid decolorization of both dyes by the EF process, but the mineralization rate was low. This low mineralization rate of $\mathrm{EF}$ process is mainly due to the higher concentration of persistent carboxylic acids and their iron-complexes. But the photolysis of this electrolyzed solution leads to almost total mineralization of dye wastewater. Ruiz et al. (2011b) used same reactor for the removal of Acid Yellow 36 from aqueous solution and observed the similar results as explained above. Degradation of Disperse Red 1 and Disperse Yellow 3 using SPEF process was examined by Salazar et al. (2011) and observed total mineralization of both dyes.

\subsection{Sonoelectro-Fenton:}

Application of ultrasound for the treatment of water and wastewater received a great attention during the recent years (Gogate et al., 2002; Sivasankar and Moholkar, 2010; Bagal and Gogate, 2014). Acoustic cavitation is the forcing phenomenal for the degradation of organic pollutants in the presence of ultrasound in water medium. It is the process of formation, growth, and succeeding collapse of microbubbles or cavities due to ultrasound in a water medium (Gogate and Pandit, 2004). The collapse of bubbles occurs within 50 ns, and the process is almost adiabatic (Chakma and Moholkar, 2013), results in the generation of higher pressure (in the range of 500-5,000 bar) and temperature (in the range of 1,000- 
$80115,000 \mathrm{~K}$ ) in the reactor (Suslick, 1989). Due to this cavitation phenomenon, hydroxyl 802 radicals are formed as given below (Li et al., 2010).

$$
\left.\left.\mathrm{H}_{2} \mathrm{O}+\right)\right) \rightarrow \mathrm{OH}^{\bullet}+\mathrm{H}^{\bullet}
$$

where ))) refers to the application of ultrasound. (Oturan et al.,2008b), results in a higher amount of radicals in the water medium and thus higher removal efficiency than EF process. In the presence of ultrasound, the electrolytically produced hydrogen peroxide dissociated into hydroxyl radicals as:

$$
\left.\left.\left.\mathrm{H}_{2} \mathrm{O}_{2}+\right)\right)\right) \rightarrow 2 \mathrm{OH}^{\bullet}
$$
process as: (1) enhanced production of hydroxyl radical and Fenton reaction kinetics by the improved mass transfer rate of both reactants (ferric ions and oxygen) towards the cathode surface for the electrochemical generation of Fenton's reagent and its transfer into the solution, (2) the additional hydroxyl radical generation by the sonolysis, and (3) pyrolysis of organics at the time of bubble explosion.

Li et al. (2010) observed an increased hydrogen peroxide production with the addition of ultrasound in EF cell. The hydrogen peroxide produced in SEF process is higher than the sum of hydrogen peroxide concentration produced from EF and sono Fenton processes. This improvement can be related to enhancement of mass transfer by sonolysis Oturan et al. (2008b).

In the presence of ultrasound, the regeneration of ferrous ions from intermediate complex produced via conventional Fenton process also occurs as in Eq. (35) (Pradhan and 823 Gogate, 2010; Bagal and Gogate, 2014). This results in an enhancement of Fenton reactions in the electrolytic cell. 
826 The arrangement of sono probe (one type of ultrasound source) and electrode also affects the

827 efficiency of SEF process. There are three types of probe-electrode arrangement (Compton et 828 al., 1997) in a sono-electrochemical reactor, namely face-on, side-on and sonotrode. Among 829 this arrangement, face-on orientation has higher mass transfer capability and is depends on 830 ultrasound power, electrode-horn distance and electrode area (Ramachandran and Saraswathi, 831 2011). These authors also tested the efficiency of angular geometry and compared with that of face-on orientation. But the mass flux values of face-on orientation are two to three times higher than that of angular geometry. Thus, face-on geometry is the better probe-electrode arrangement in a SEF reactor. This arrangement reduces the layer formation on the cathode surface and enhances the efficiency of SEF process. Thus the enhancement in the efficiency of SEF process is mainly due to physical and chemical mechanisms (Babuponnusami and Muthukumar, 2012). Physical mechanism related to the high mixing and electrode surface cleaning by the addition of ultrasound in the EF reactor. This enhances the mass transfer between electrode and solution in addition to higher hydrogen peroxide production. The chemical mechanism is due to the additional radical formation in the cell as explained above. solution. An enhancement in hydrogen peroxide production and dye removal rate with the addition of ultrasound in EF process was observed by Li et al. (2010b). Authors concluded that in SEF process, low frequency ultrasound has a positive effect on dye mineralization. The rate of dye removal by SEF process is 10 fold higher than that of sonolysis and 2 fold higher than that of conventional Fenton process (Martínez and Uribe, 2012). Abatement of reactive blue 19 dye using SEF process was investigated by Siddique et al. (2011). The authors observed an almost complete removal of dye and $56.47 \%$ of TOC from unhydrolyzed reactive blue 19 dye solution at a frequency of $80 \mathrm{kHz}$. At the same time, $81 \%$ of 
850 TOC removal was observed for hydrolyzed reactive blue 19 solution. Similar way, $85 \%$ of

851 TOC and more than $90 \%$ of color introduced by azure B were removed efficiently by SEF 852 process in the presence of reticulated vitreous carbon cathode and platinum gauze counter 853 electrode (Martínez and Uribe, 2012). Oturan et al. (2008b) observed a synergistic effect in 854 SEF process (compared to EF process) in degradation of azobenzene at low frequencies (i.e. 20 and $6080 \mathrm{kHz}$ ) and an improvement in degradation kinetics for early treatment times.

856 Similarly, Şahinkaya (2013) observed a negligible increase in treatment efficiency of SEF process, when compared with the capital and operating costs of sonication. Lounis et al. (2016) examined the performance of SEF for the degradation of Orange $G$ in various water mediums like pure water, natural water and seawater. The dye removal rate was very high in sea water medium followed by pure water and natural mineral water. Complete dye removal was observed for sea water and pure water medium, while $94 \%$ of dye removal was observed for natural mineral water medium.

\subsection{Bioelectro Fenton}

Two versions of bioelectro-Fenton were reported: (i) bioelectro-Fenton (BEF) based on bio-electrochemical reactor proposed by Zhu and Ni (2009) consisting of two cells: microbial fuel cell (MFC) containing biodegradable organic substrates and anodic Fenton treatment (AFT) cell containing pollutants to be degraded by EF process, and (ii) BEF consisting of coupling between EF process and microbial degradation (Olvera-Vargas et al., 2016a, b). EF step being utilized as pre-treatment for mineralization of beta-blocker drug metoprolol: $1 \mathrm{~h}$ EF pre-treatment step followed by aerobic biodegradation allowed $90 \%$ mineralization at 4 days. On the other hand, Ganzenko et al., (2017) investigated the use of BEF during treatment of a pharmaceutical wastewater treatment in two scenarios: EF as both pre- 
treatment and post-treatment of biological step and found and found first scenario more efficient.

Feng et al. (2010b) used BEF system containing anaerobic anode chamber having Shewanella decolorationis S12 as microorganism for the generation of electricity and carbon nanotube $(\mathrm{CNT}) / \gamma$-FeOOH composite cathode for the production of hydrogen peroxide. The authors used this system for the abatement of orange II and observed a complete decolorization and mineralization of dye. A maximum power output of $230 \mathrm{~mW} \mathrm{~m}^{-2}$ was also obtained from the BEF system. But modification of BEF system with polypyrrole/anthraquinone-2,6-disulfonate (PPy/AQDS) conductive film boosted the performance of the system. Feng et al. (2010a) observed a maximum power density of 823 $\mathrm{mW} \mathrm{m}^{-2}$ by the use this conductive film.

MFC is a "renewable energy device that converts energy available in organic compounds to electricity via the canalization of microorganisms" (Feng et al., 2010a). The biodegradable organic substance generally used in an MFC is glucose or acetate. Microorganisms present on the anode compartment oxidize these substrates and generates protons and electrons (Zhu and Logan, 2013). The electrons produced via this oxidation process flow through an external circuit to cathode. At the same time, the protons released into the solution. At the cathode surface, oxygen reacts with both proton and electron, forms water as in Eq. (36).

$$
\mathrm{O}_{2}+4 \mathrm{H}^{+}+4 \mathrm{e}^{-} \rightarrow 2 \mathrm{H}_{2} \mathrm{O}
$$

Besides the electricity generation, MFC have several other advantages. Self-regeneration capacity of microorganism reduces the catalyst cost in MFC compared to conventional chemical fuel cells (Fernándezde Dios et al., 2013). Absence of pollutant generation 
897 (including all toxic substances) during any operations in MFC makes this cell as an 898 environmentally friendly energy system (Gong et al., 2011).

900 open circuit and this low-voltage electricity can be used for other electrolytic process like

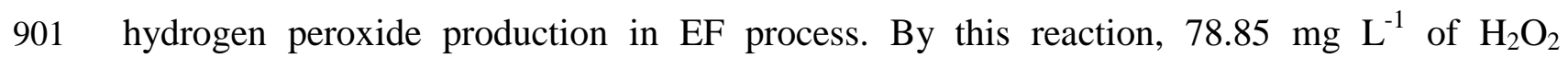
902 production in the cell after $12 \mathrm{~h}$ of electrolysis was observed by Fu et al. (2010b). This 903 hydrogen peroxide undergoes conventional Fenton's reaction and produces ${ }^{\circ} \mathrm{OH}$. But in BEF, 904 the production of hydrogen peroxide requires only two-electron transfer. Thus a BEF system generates electricity, produces ${ }^{\circ} \mathrm{OH}$ in cathodic compartment and causes degradation of organic pollutants. The working principles of a BEF system are shown in Fig. 5.

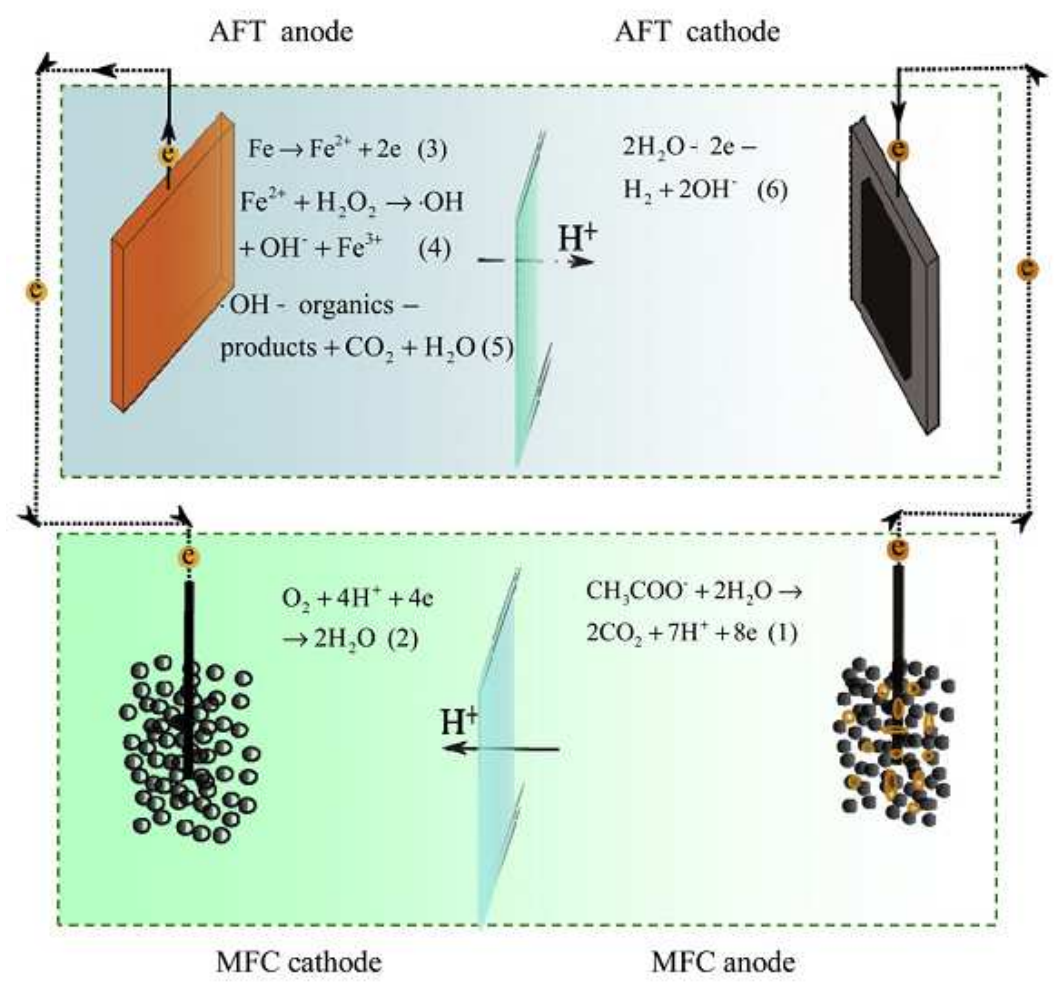

Fig. 5 Energy generation and subsequent pollutant removal reactions in MFC assisted-AFT system. Reprinted with permission from Liu et al., (2012). Copyright 2012, Elsevier. 

was examined by Fernández de Dios et al. (2013). The authors carried out the experiments

912 both in batch and continuous flow mode for the removal of lissamine green B and crystal 913 violet from aqueous solution. $94 \%$ of lissamine green B and $83 \%$ of crystal violet removals 914 were observed by the researchers after $9 \mathrm{~h}$ of electrolysis in MFC combined with in situ EF process. For this condition, respective TOC amounts of $82 \%$ and $70 \%$ were removed from the same BEF reactor respectively for lissamine green and crystal violet. At the same time more than $95 \%$ of dye removal and $85 \%$ of TOC removal were observed in a bubble column reactor used in MFC combined with ex situ EF process. hydrogen peroxide and eliminating its residual concentration (Fig. 6). The investigators achieved this by alternating switching between microbial electrolysis cell (MEC) and microbial fuel cell (MFC). In MEC mode of operation, degradation of pollutants occurs by the electrolytic generation of $\mathrm{H}_{2} \mathrm{O}_{2}$ and subsequent generation of hydroxyl radicals by the reaction with ferrous ions. The residual hydrogen peroxide after the MEC mode of operation consumes during the MFC mode of operation, by using hydrogen peroxide as electron acceptor. The authors tested the efficiency of this BEF system for the abatement of $50 \mathrm{mg} \mathrm{L}^{-1}$ methylene blue solution. Almost complete decolorization and mineralization of the dye solution were achieved after $8 \mathrm{~h}$ and $16 \mathrm{~h}$ in MEC mode of operation. The residual hydrogen

929 peroxide concentration was observed as $180 \mathrm{mg} \mathrm{L}^{-1}$ and this was consumed completely in 930 MFC mode of operation within $39 \mathrm{~h}$ of operation. wastewater (Roshini et al., 2017). Combined EF and aerobic-microaerophilic process is able 
934 COD, $52.7 \%$ color and $41 \%$ TOC were removed by EF process followed by aerobic 935 microbial process..

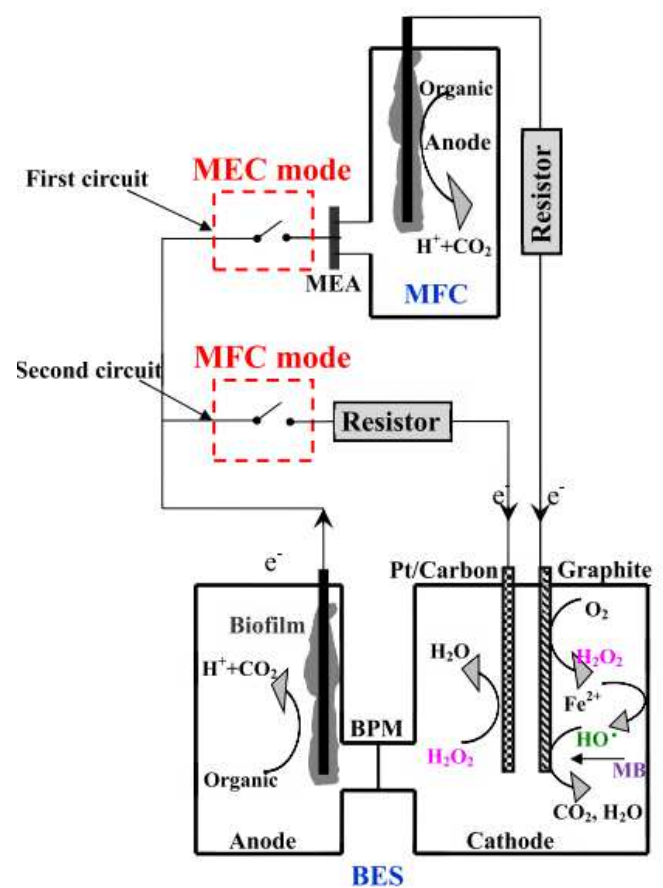

937 Fig. 6 BEF reactor with alternate switching, where MEC: microbial electrolysis cell; MFC:

938 microbial fuel cell; MEA: membrane electrode assembly; BES: bioelectrochemical system;

939 BPM: bipolar membrane. Reprinted with permission from Zhang et al. (2015). Copyright 2015, Elsevier

\section{Scale up of EAOPs cells}

Application of EAOPs for the abatement of dyes was largely investigated at lab scale.

943 A few studies were investigated even in continuous flow mode of operation, which resembles

944 the practical conditions for the dye wastewater treatment. The next step of investigation is 945 pilot scale studies for dye removal by EAOPs. The scale up of an electrolytic reactor depends 946 on its geometric, kinematic, current/potential and thermal similarity between the reactors 947 (Gupta and Oloman, 2006). Geometric similarity can be achieved by keeping the dimensional 948 ratios as constant. But it is not advisable to increase the inner electrode spacing. Because, 949 with increase in electrode spacing, the ohmic drop between electrodes increases, which 
950 results in reduction in the efficiency of EAOPs. The increased spacing requires higher

951 voltages for the optimal operation and this increases the energy consumption of the cell,

952 consequently increases the cost of operation. Therefore, during scale up process of

953 electrolytic reactors, geometric similarity is usually sacrificed in favor of current/potential

954 similarity (Gupta and Oloman, 2006). Current/potential similarity is also known as electrical

955 similarity; which can be achievable by keeping constant differences in electrode potential and 956 current density (Goodridge and Scott, 1994). This can be achieved by keeping a constant

957 inner electrode gap during scale up process. The kinematic similarity depends on the inlet 958 flow rate and this similarity can be achievable by keeping same residence time or flow rate 959 during the scale up process. Thermal similarity is another important parameter to be 960 considered during the scale up process. Most of the lab scale works were carried out at the 961 room temperature. But the effluents from the textile industry have the temperature near to the $962100{ }^{\circ} \mathrm{C}$. Therefore, a mismatching between the lab scale efficiency and real field efficiency 963 will occurs. Because in the case of Fenton based EAOPs, the elevated temperature decreases 964 the stability of oxygen and hydrogen peroxide. This decreases the efficiency of EAOPs at 965 elevated temperature.

\section{Conclusions and perspectives}

EAOPs have a great potential to remove dyes from water medium. Comparing to direct EAOPs, indirect EAOPs, especially that based on Fenton chemistry has received increased 970 attention in the last decade. AO process, a well-known direct EAOPs, is also very efficient to 971 remove dyes from aqueous solution. The higher cost of high oxygen over potential anode is one of the main drawbacks of this process. Various types of Fenton process based EAOPs, naming EF, PEF, SEF, peroxi-coagulation, fered Fenton, anodic Fenton etc. have been applied effectively for the removal of dyes. Total decolorization of dyes has been achieved in 
most of the cases. But the mineralization efficiency is, in general, less than that of decolorization efficiency. This is mainly due to the less degradation rate of by-products in all the EAOPs. Ferrous ion is found as an efficient catalyst among various forms of iron for the removal of dyes in $\mathrm{EF}$ and related processes. EF like reactions, heterogeneous $\mathrm{EF}$ and 3D EF

979 processes are the new trends in dye removal by EF based processes. The external addition of 980 iron salt has been replaced with sacrificial iron anode in peroxi-coagulation process. But the 981 sludge production and increased passivation rate of electrodes decreases the degradation efficiency of this process. The efficiency of EF process has been increased significantly by the addition of UV light (PEF) and ultrasound (SEF). The rate of removal of PEF and SEF 984 processes are generally higher than that of EF process, but these latest processes are more 985 costly because of coupling with highly energy consuming processes. The practical 986 implementation of PEF process has been simplified by the introduction of solar energy 987 (SPEF). Combined biological process and EAOPs is also a new trend in this field. In BEF, 988 electricity produced from MFC has been used for the production of hydroxyl radicals. But the 989 time taken for the removal of dyes by BEF is much higher than that of EF process.

990 Scale up of EAOPs is a global problem, even though these processes are very efficient 991 and cheap. Electrical similarity is the major factor to be remembered during scale up 992 operations. Since, this is very important for the real implementation of EAOPs, more works on dye removal by EAOPs in industrial scale is required. Overall, it can be concluded that

994 EAOPs constitute a promising technology for the removal of dyes from aqueous solution. 


\section{References}

Abdessamad, N., Akrout, H., Hamdaoui, G., Elghniji, K., Ksibi, M., Bousselmi, L., 2013. Evaluation of the efficiency of monopolar and bipolar BDD electrodes for electrochemical oxidation of anthraquinone textile synthetic effluent for reuse. Chemosphere 93, 13091316.

Abo-Farha, S.A., 2010. Comparative study of oxidation of some azo dyes by different advanced oxidation processes: Fenton, Fenton-like, photo-Fenton, and photo-Fenton-like. J. Am. Sci. 6 (10), 128-142.

Almeida, L.C., Garcia-Segura, S., Arias, C., Bocchi, N., Brillas, E., 2012. Electrochemical mineralization of the azo dye acid red 29 (Chromotrope 2R) by photoelectro-Fenton process. Chemosphere 89 (6), 751-758.

Almomani, F., Baranova, E.A., 2013. Kinetic study of electro-Fenton oxidation of azo dyes on boron-doped diamond electrode. Environ. Technol. 34 (11), 1473-1479.

Ammar, S., Oturan, M.A., Labiadh, L., Guersalli, A., Abdelhedi, R., Oturan, N., Brillas, E., 2015. Degradation of tyrosol by a novel electro- Fenton process using pyrite as heterogeneous source of iron catalyst. Water Res. 74, 77-87.

An, H., Cui, H., Zhang, W., Zhai, J., Qian, Y., Xie, X., Li, Q., 2012. Fabrication and electrochemical treatment application of a microstructured $\mathrm{TiO}_{2}-\mathrm{NTs} / \mathrm{Sb}-\mathrm{SnO}_{2} / \mathrm{PbO}_{2}$ anode in the degradation of C.I. reactive blue 194 (RB 194). Chem. Eng. J. 209, 86-93.

Andrade, L.S., Tasso, T.T., da Silva, D.L., Rocha-Filho, R.C., Bocchi, N., Biaggio, S.R., 2009. On the performances of lead dioxide and boron-doped diamond electrodes in the anodic oxidation of simulated wastewater containing the reactive orange 16 dye. Electrochim. Acta 54 (7), 2024-2030.

Anglada, A., Urtiaga, A., Ortiz, I., 2009, Contributions of electrochemical oxidation to wastewater treatment: fundamentals and review of applications. J. Chem. Technol. Biotechnol. 84 (12), 1747-1755.

Aquino, J.M., Rocha-Filho, R.C., Rodrigo, M.A., Sáez, C., Cañizares, P., 2013. Electrochemical degradation of the reactive red 141 dye using a boron-doped diamond anode. Water Air Soil Pollut. 224, 1397.

Aquino, J.M., Rodrigo, M.A., Rocha-Filho, R.C., Saez, C., Cañizares, P., 2012. Influence of the supporting electrolyte on the electrolyses of dyes with conductive-diamond anodes. Chem. Eng. J. 184, 221-227.

Arivoli, S., Thenkuzhali, M., Martin Deva Prasath, P., 2009. Adsorption of rhodamine B by acid activated carbon- Kinetic, thermodynamic and equilibrium studies. Orbital 1 (2), 138155.

Babuponnusami, A., Muthukumar, K., 2012. Advanced oxidation of phenol: A comparison between Fenton, electro-Fenton, sono-electro-Fenton and photo-electro-Fenton processes. Chem. Eng. J. 183, 1-9. 
Bae, J.-S., Freeman, H.S., 2007. Aquatic toxicity evaluation of copper-complexed direct dyes to the Daphnia magna. Dyes Pigments 73 (1), 126-132.

Bagal, M.V., Gogate, P.R., 2014. Wastewater treatment using hybrid treatment schemes based on cavitation and Fenton chemistry: A review. Ultrason.Sonochem.21 (1), 1-14.

Bahnemann, D., 2004. Photocatalytic water treatment: solar energy applications. Sol. Energy 77 (5), 445-459.

Balci, B., Oturan, M.A., Oturan, N., Sirés, I., 2009. Decontamination of aqueous glyphosate, (aminomethyl) phosphonic acid, and glufosinate solutions by electro-Fenton-like process with $\mathrm{Mn}^{2+}$ as the catalyst. J. Agr. Food Chem., 57(11), 4888-4894.

Barhoumi, N., Labiadh, L., Oturan, M.A., Oturan, N., Gadri, A., Ammar, S., Brillas, E., 2015. Electrochemical mineralization of the antibiotic levofloxacin by electro-Fentonpyrite process. Chemosphere 141, 250-257.

Barhoumi, N., Oturan, N., Olvera-Vargas, H., Brillas, E., Gadri, A., Ammar, S., Oturan, M.A., 2016. Pyrite as a sustainable catalyst in electro-Fenton process for improving oxidation of sulfamethazine. Kinetics, mechanism and toxicity assessment. Water Res. 94, $52-61$.

Barredo-Damas, S., Alcaina-Miranda, M.I., Iborra-Clar, M.I., Bes-Pia, A., Mendoza-Roca, J.A., Iborra-Clar, A., 2006. Study of the UF process as pretreatment of NF membranes for textile wastewater reuse. Desalination 200 (1-3), 745-747.

Bedolla-Guzman, A., Sirés, I., Thiam, A., Peralta-Hernández, J.M., Gutiérrez-Granados, S., Brillas, E., 2016. Application of anodic oxidation, electro-Fenton and UVA photoelectroFenton to decolorize and mineralize acidic solutions of Reactive Yellow 160 azo dye. Electrochim. Acta 206, 307-316

Benfield, L.D., Weand, B.L., Judkins, J.F., 1982.Process chemistry for water and wastewater. Prentice Hall Inc, Englewood Cliffs, New Jersey.

Bensalah, N., Quiroz Alfaro, M.A., Martínez-Huitle, C.A., 2009. Electrochemical treatment of synthetic wastewaters containing Alphazurine A dye. Chem. Eng. J. 149, 348-352.

Bogdanowicz, R., Fabiańska, A., Golunski, L., Sobaszek, M., Gnyba, M., Ryl, J., Darowicki, K., Ossowski, T., Janssens, S.D., Haenen, K., Siedlecka, E.M., 2013, Influence of the boron doping level on the electrochemical oxidation of the azo dyes at Si/BDD thin film electrodes. Diam. Relat. Mater. 39, 82-88.

Braga, N.A., Cairo, C.A.A., Matsushima, J.T., Baldan, M.R., Ferreira, N.G., 2010. Diamond/porous titanium three-dimensional hybrid electrodes. J. Solid State Electrochem. $14,313-321$.

Brillas, E., 2014. A Review on the degradation of organic pollutants in waters by UV photoelectro-Fenton and solar photoelectro-Fenton. J. Braz. Chem. Soc. 25 (3), 393-417.

Brillas, E., Casado, J., 2002. Aniline degradation by electro-Fenton and peroxi-coagulation processes using a flow reactor for wastewater treatment. Chemosphere 47 (3), 241-248. 
Brillas, E., Mur, E., Casado, J., 1996. Iron(II) catalysis of the mineralization of aniline using a carbon-PTFE $\mathrm{O}_{2}$-fed cathode. J. Electrochem. Soc.143 (3), L49-L53.

Brillas, E., Mur, E., Sauleda, R., Sanchez, L., Peral, J., Domenech, X., Casado, J., 1998. Aniline mineralization by AOP's: anodic oxidation, photocatalysis, electro-Fenton and photoelectro-Fenton processes. Appl. Catal. B-Environ. 16, 31-42.

Brillas, E., Sauleda, R., Casado, J., 1997. Peroxi-coagulation of aniline in acidic medium using an oxygen diffusion cathode. J. Electrochem. Soc. 144 (7), 2374 - 2379.

Brillas, E., Sauleda, R., Casado, J., 1998. Degradation of 4-chlorophenol by anodic oxidation, electro-Fenton, photoelectro-Fenton, and peroxi-coagulation processes. J. Electrochem. Soc., 145, 759-765.

Canizares, P., Gadri, A., Lobato, J., Nasr, B., Paz, R., Rodrigo, M.A., Saez, C., 2009. Electrochemical oxidation of azoic dyes with conductive-diamond anodes. Ind. Eng. Chem. Res. 45 (10), 3468-3473.

Chakma, S., Moholkar, V.S., 2013. Physical mechanism of sono-Fenton process. AIChE J. 59 (11), 4303-4313.

Chen, G., 2004. Electrochemical technologies in wastewater treatment. Sep. Purif. Technol. 38 (1), 11-41.

Chen, X., Chen, G., Yue, P.L., 2003. Anodic oxidation of dyes at novel Ti/B-diamond electrodes. Chem. Eng. Sci. 58 (3-6), 995 - 1001.

COINDS, 2000. Comprehensive industry documents series on textile industry. Central Pollution Control Board, India 59, 1999-2000.

Comninellis, C., 1994. Electrocatalysis in the electrochemical conversion/combustion of organic pollutants for waste water treatment. Electrochim. Acta 39 (11-12), 1857-1862.

Comninellis, C., De Battisti, A., 1996. Electrocatalysis in anodic oxidation of organics with simultaneous oxygen evolution. J. Chim. Phys. 93 (4), 673-679.

Compton, R.G., Eklund, J. C., Marken, F., 1997. Sonoelectrochemical Processes: A review. Electroanal. 9 (7), 509-522.

Couto, S.R., 2009. Dye removal by immobilised fungi. Biotechnol. Adv. 27 (3), 227-235.

Crini, G., 2006. Non-conventional low-cost adsorbents for dye removal: A review. Bioresource Technol. 97 (9), 1061-1085.

Demirbas, A., 2009. Agricultural based activated carbon for the removal of dyes from aqueous solutions: A review. J. Hazard. Mater.167 (1-3), 1-9.

Diagne, M., Sharma, V.K., Oturan, N., Oturan, M.A., 2014. Depollution of indigo dye by anodic oxidation and electro-Fenton using B-doped diamond anode. Environ. Chem. Lett. 12, 219-224.

do Vale-Júnior, E., Dosta, S., Cano, I.G., Guilemany, J.M., Garcia-Segura, S., MartínezHuitle, C.A., 2016. Acid blue 29 decolorization and mineralization by anodic oxidation with a cold gas spray synthesized $\mathrm{Sn}-\mathrm{Cu}-\mathrm{Sb}$ alloy anode. Chemosphere 148, 47-54 
dos Santos, A.J., de Lima, M.D., da Silva, D.R., Garcia-Segura, S., Martínez-Huitle, C.A., 2016. Influence of the water hardness on the performance of electro-Fenton approach: Decolorization and mineralization of Eriochrome Black T. Electrochim. Acta 208, 156163.

Drogui, P., Asselin, M., Brar, S.K., Benmoussa, H., Blais, J.F., 2008. Electrochemical removal of pollutants from agro-industry wastewaters. Sep. Purif. Technol. 61 (3), 301310.

El-Desoky, H.S., Ghoneim, M.M., El-Sheikh, R., Zidan, N.M., 2010.Oxidation of levafix CA reactive azo-dyes in industrial wastewater of textile dyeing by electro-generated Fenton's reagent. J. Hazard. Mater. 175 (1-3), 858-865.

El-Ghenymy, A., Centellas, F., Rodríguez, R.M., Cabot, P.L., Garrido, J.A., Sirés, I., Brillas, E., 2015. Comparative use of anodic oxidation, electro-Fenton and photoelectro-Fenton with Pt or boron-doped diamond anode to decolorize and mineralize Malachite Green oxalate dye. Electrochim. Acta 182, 247-256

El-Kacemi, S., Zazou, H, Oturan, N., Dietze, M., Hamdani, M., Es-Souni, M., Oturan, M.A., 2017. Nanostructured $\mathrm{ZnO}-\mathrm{TiO}_{2}$ thin film oxide as anode material in electrooxidation of organic pollutants. Application to the removal of dye Amido black 10B from water. Environ. Sci. Pollut. Res. 24, 1442-1449.

Eslami, A., Moradi, M., Ghanbari, F., Mehdipour, F., 2013. Decolorization and COD removal from real textile wastewater by chemical and electrochemical Fenton processes: a comparative study. J. Environ. Health Sci. Eng. 11, 31.

Faouzi, A.M., Nasr, B., Abdellatif, G., 2007, Electrochemical degradation of anthraquinone dye Alizarin Red S by anodic oxidation on boron-doped diamond. Dyes Pigments 73 (1), 86-89.

Feng, C., Li, F., Liu, H., Lang, X., Fan, S, 2010a. A dual-chamber microbial fuel cell with conductive film-modified anode and cathode and its application for the neutral electroFenton process. Electrochim. Acta 55 (6), 2048-2054.

Feng, C-H., Li, F-B., Mai, H-J., Li, X-Z., 2010b. Bio-electro-Fenton process driven by microbial fuel cell for wastewater treatment. Environ. Sci. Technol. 44 (5), 1875-1880.

Fernández de Dios, M.Á., González del Campo, A., Fernández, F.J., Rodrigo, M., Pazos, M., Sanromán, M.Á., 2013. Bacterial-fungal interactions enhance power generation in microbial fuel cells and drive dye decolourisation by an ex situ and in situ electro-Fenton process. Bioresource Technol. 148, 39-46.

Flox, C., Arias, C., Brillas, E., Savall, A., Groenen-Serrano, K., 2009. Electrochemical incineration of cresols: a comparative study between $\mathrm{PbO}_{2}$ and boron-doped diamond anodes. Chemosphere 74 (10), 1340-1347.

Flox, C., Cabot, P.L., Centellas, F., Garrido, J.A., Rodríguez, R.M., Arias, C., Brillas, E., 2007a. Solar photoelectro-Fenton degradation of cresols using a flow reactor with a borondoped diamond anode. Appl. Catal. B: Environ. 75 (1-2), 17-28. 
Flox, C., Garrido, J.A., Rodríguez, R.M., Cabot, P.L., Centellas, F., Arias, C., Brillas, E., 2007b. Mineralization of herbicide mecoprop by photoelectro-Fenton with UVA and solar light. Catal. Today 129 (1-2), 29-36.

Flox, C., Garrido, J.A., Rodríguez, R.M., Centellas, F., Cabot, P.L., Arias, C., Brillas, E., 2005. Degradation of 4,6-dinitro-o-cresol from water by anodic oxidation with a borondoped diamond electrode. Electrochim. Acta 50 (18), 3685-3692.

Fu, F., Wang, Q., Tang, B., 2010a. Effective degradation of CI Acid Red 73 by advanced Fenton process. J. Hazard. Mater.174 (1-3), 17-22.

Fu, L., You, S., Yang, F., Gao, M., Fang, X., Zhang, G., 2010b. Synthesis of hydrogen peroxide in microbial fuel cell. J. Chem. Technol. Biotechnol. 85 (5), 715-719.

Ganzenko, O., Trellu, C., Papirio, S., Oturan, N., Huguenot, D., van Hullebusch, E.D., Esposito, G., Oturan, M.A. (2017). Bioelectro-Fenton: evaluation of a combined biological-advanced oxidation treatment for pharmaceutical wastewater. Environ. Sci. Pollut. Res. (in press), doi: 10.1007/s11356-017-8450-6.

Garcia-Segura, S., Brillas, E., 2016. Combustion of textile monoazo, diazo and triazo dyes by solar photoelectro-Fenton: Decolorization, kinetics and degradation routes. Appl. Catal. B: Environ. 181, 681-691

Garcia-Segura, S., El-Ghenymy, A., Centellas, F., Rodríguez, R.M., Arias, C., Garrido, J.A., Cabot, P.L., Brillas, E., 2012. Comparative degradation of the diazo dye Direct Yellow 4 by electro-Fenton, photoelectro-Fenton and photo-assisted electro-Fenton. J. Electroanal. Chem. 681, 36-43.

Garcia-Segura, S., Salazar, R., Brillas, E., 2013. Mineralization of phthalic acid by solar photoelectro-Fenton with a stirred boron-doped diamond/air-diffusion tank reactor: Influence of $\mathrm{Fe}^{3+}$ and $\mathrm{Cu}^{2+}$ catalysts and identification of oxidation products. Electrochim. Acta 113, 609-619.

George, S.J., Gandhimathi, R., Nidheesh, P.V., Ramesh, S.T., 2013. Oxidation of salicylic acid from aqueous solution with continuous stirred tank reactor by electro-Fenton method. Environ. Eng. Sci. 30 (12), 757-764.

George, S.J., Gandhimathi, R., Nidheesh, P.V., Ramesh, S.T., 2014. Electro-Fenton oxidation of salicylic acid from aqueous solution: Batch studies and degradation pathway. Clean Soil Air Water 42(1), 1701-1711.

George, S.J., Gandhimathi, R., Nidheesh, P.V., Ramesh, S.T., 2016. Optimization of salicylic acid removal by electro Fenton process in a continuous stirred tank reactor using response surface methodology. Desalination Water Treat. 57, 4234-4244.

Ghoneim, M.M., El-Desoky, H.S., Zidan, N.M., 2011. Electro-Fenton oxidation of Sunset Yellow FCF azo-dye in aqueous solutions. Desalination 274 (1-3), 22-30.

Ghosh, P., Thakur, L.K., Samanta, A.N., Ray, S., 2012. Electro-Fenton treatment of synthetic organic dyes: Influence of operational parameters and kinetic study. Korean J. Chem. Eng. 29 (9), 1203-1210. 
Girish Kumar, S., Gomathi Devi, L., 2011. Review on modified $\mathrm{TiO}_{2}$ photocatalysis under UV/visible light: Selected results and related mechanisms on interfacial charge carrier transfer dynamics. J. Phys. Chem. A 115 (46), 13211-13241.

Gogate, P.R., Pandit, A.B., 2004. A review of imperative technologies for wastewater treatment II: Hybrid methods. Adv. Environ. Res. 8 (3-4), 553-597.

Gogate, P.R., Tatake, P.A., Kanthale, P.M., Pandit, A.B., 2002. Mapping of sonochemical reactors: Review, analysis, and experimental verification. AIChE J. 48 (7), 1542-1560.

Gong, R., Jin, Y., Chen, J., Hu, Y., Sun, J., 2007. Removal of basic dyes from aqueous solution by sorption on phosphoric acid modified rice straw. Dyes Pigments 73 (3), 332337.

Gong, Y., Radachowsky, S.E., Wolf, M., Nielsen, M.E., Girguis, P.R., Reimers, C.E., 2011. Benthic microbial fuel cell as direct power source for an acoustic modem and seawater oxygen/temperature sensor system. Environ. Sci. Technol. 45 (11), 5047-5053.

Goodridge, F., Scott, K., 1994. Electrochemical Process Engineering, Plenum Press, New York.

Gözmen, B., Kayan, B., Murat Gizir, A., Hesenov, A., 2009. Oxidative degradations of reactive blue 4 dye by different advanced oxidation methods. J. Hazard. Mater.168 (1), $129-136$.

Guivarch, E., Oturan M.A., 2004. The problem of the contamination of waters by synthetic dyes: how to destroy them? Application of the electro-Fenton process.Actual. Chimique 277-278, 65-69.

Guivarch, E., Trévin, S., Lahitte, C., Oturan M.A., 2003. Degradation of azo dyes in water by electro-Fenton process. Environ. Chem. Lett. 1(1), 39-44.

Gupta, N., Oloman, C.W., 2006. Scale-up of the perforated bipole trickle-bed electrochemical reactor for the generation of alkaline peroxide. J. Appl. Electrochem. 36, 1133-1141.

Haidar, M., Dirany, A., Sirés, I., Oturan, N., Oturan, M.A., 2013. Electrochemical degradation of the antibiotic sulfachloropyridazine by hydroxyl radicals generated at a BDD anode. Chemosphere 91 (9), 1304-1309.

Hammami, S., Oturan, N., Bellakhal, N., Dachraoui, M., Oturan, M.A. 2007. Oxidative degradation of direct orange 61 by electro-Fenton process using a carbon felt electrode: Application of the experimental design methodology. J. Electroanal. Chem. 610 (1), 7584.

Hu, Z., Zhou, M., Zhou, L., Li, Y., Zhang, C. 2014. Effect of matrix on the electrochemical characteristics of $\mathrm{TiO}_{2}$ nanotube arrays based $\mathrm{PbO}_{2}$ electrode for pollutant degradation. Environ. Sci. Pollut. Res. 21, 8476-8484.

Iglesias, O., Fernández de Dios, M.A., Pazos, M., Sanromán, M.A., 2013a. Using iron-loaded sepiolite obtained by adsorption as a catalyst in the electro-Fenton oxidation of Reactive Black 5. Environ. Sci. Pollut. Res. 20 (9), 5983-5993. 
Iglesias, O., Rosales, E., Pazos, M., Sanromán, M.A., 2013b. Electro-Fenton decolourisation of dyes in an airlift continuous reactor using iron alginate beads. Environ. Sci. Pollut. Res. 20 (4), 2252-2261.

Iranifam, M., Zarei, M., Khataee, A.R., 2011. Decolorization of C.I. Basic Yellow 28 solution using supported $\mathrm{ZnO}$ nanoparticles coupled with photoelectro-Fenton process. J. Electroanal. Chem. 659 (1), 107-112.

Isarain-Chávez, E., de la Rosa, C., Martínez-Huitle, C.A., Peralta-Hernández, J.M., 2013. Onsite hydrogen peroxide production at pilot flow plant: Application to electro-Fenton process. Int. J. Electrochem. Sci. 8, $3084-3094$.

Ji, F., Li, C., Zhang, J., Deng, L., 2011. Efficient decolorization of dye pollutants with $\mathrm{LiFe}\left(\mathrm{WO}_{4}\right)_{2}$ as a reusable heterogeneous Fenton-like catalyst. Desalination 269 (1-3), 284-290.

Ju, D.J., Byun, I.G., Park, J.J., Lee, C.H., Ahn, G.H., Park, T.J., 2008. Biosorption of a reactive dye (Rhodamine-B) from an aqueous solution using dried biomass of activated sludge. Bioresour. Technol. 99 (17), 7971-7975.

Jüttner, K., Galla, U., Schmieder, H., 2000. Electrochemical approaches to environmental problems in the process industry. Electrochim. Acta 45 (15-16), 2575-94.

Karthikeyan, S., Jambulingam, M., Sivakumar, P., Shekhar, A.P., Krithika, J., 2006. Impact of textile effluents on fresh water fish Mastacembelus Armatus (Cuv.\& Val). E-J. Chem. 3 (4), 303-306.

Kavitha, V., Palanivelu, K., 2004. The role of ferrous ion in Fenton and photo-Fenton processes for the degradation of phenol. Chemosphere 55 (9), 1235-1243

Kayan, B., Gözmen, B., Demirel, M., Murat Gizir, A., 2010. Degradation of acid red 97 dye in aqueous medium using wet oxidation and electro-Fenton techniques. J. Hazard. Mater.177 (1-3), 95-102.

Khataee, A.R., Vahid, B., Behjati, B., Safarpour, M., Joo, S.W., 2014. Kinetic modeling of a triarylmethane dye decolorization by photoelectro-Fenton process in a recirculating system: Nonlinear regression analysis. Chem. Eng. Res. Des. 92 (2), 362-367.

Khataee, A.R., Vatanpour, V., Amani Ghadim, A.R., 2009. Decolorization of C.I. Acid Blue 9 solution by UV/nano- $\mathrm{TiO}_{2}$, Fenton, Fenton-like, electro-Fenton and electrocoagulation processes: a comparative study. J. Hazard. Mater.161 (2-3), 1225-1233.

Khataee, A.R., Zarei, M., 2011. Photocatalysis of a dye solution using immobilized ZnO nanoparticles combined with photoelectrochemical process. Desalination 273 (2-3), 453460 .

Khataee, A.R., Zarei, M., Asl, S.K., 2010b. Photocatalytic treatment of a dye solution using immobilized $\mathrm{TiO}_{2}$ nanoparticles combined with photoelectro-Fenton process: Optimization of operational parameters. J. Electroanal. Chem. 648 (2), 143-150. 
Khataee, A.R., Zarei, M., Moradkhannejhad, L., 2010a. Application of response surface methodology for optimization of azo dye removal by oxalate catalyzed photoelectroFenton process using carbon nanotube-PTFE cathode. Desalination 258 (1-3), 112-119.

Klemola, K., Honkalampi-Hämäläinen, U., Liesivuori, J., Pearson, J., Lindström-Seppä, P., 2006. Evaluating the toxicity of reactive dyes and fabrics with the spermatozoa motility inhibition test. Autex Res. J. 6 (3), 182-190.

Klemola, K., Pearson, J., Lindstrom-Seppä, P., 2007. Evaluating the toxicity of reactive dyes and dyed fabrics with the HaCaT cytotoxicity test. Autex Res. J. 7 (3), 217-223.

Kwon, B.G., Lee, D.S., Kang, N., Yoon, J., 1999. Characteristics of p-chlorophenol oxidation by Fenton's reagent.Water Res. 33 (9), 2110-2118.

Labiadh, L., Oturan, M.A., Panizza, M., Ben Hamadi, N., Ammar, S., 2015. Complete removal of AHPS synthetic dye from water using new electro-Fenton oxidation catalyzed by natural pyrite as heterogeneous catalyst. J. Hazard. Mater. 297, 34-41

Labiadh, L., Barbucci, A., Carpanese, M.P., Gadri, A., Ammar, S., Panizza, M., 2016. Comparative depollution of Methyl Orange aqueous solutions by electrochemical incineration using TiRuSnO$, 3, \mathrm{BDD}$ and $\mathrm{PbO}_{2}$ as high oxidation power anodes. J. Electroanal. Chem. 766, 94-99.

Lahkimi, A., Oturan, M.A., Oturan, N., Chaouch, M., 2007. Removal of textile dyes from water by the electro-Fenton process. Environ. Chem. Lett. 5, 35-39.

Lam, S-M., Sin, J-C., Abdullah, A.Z., Mohamed, A.R., 2012. Degradation of wastewaters containing organic dyes photocatalysed by zinc oxide: A review. Desalination Water Treat. 41 (1-3), 131-169.

Le, T.X.H., Bechelany, M., Lacour, S., Oturan, N., Oturan, M.A., Cretin, M., 2015. High removal efficiency of dye pollutants by electron-Fenton process using a graphene based cathode. Carbon 94, 1003-1011

Le, T.X.H., Nguyen, T.V., Yacouba, Z.A., Zoungrana, L., Avril, F., Petit, E., Mendret, J., Bonniol, V., Bechelany, M., Lacour, S., Lesage, G., Cretin, M., 2016. Toxicity removal assessments related to degradation pathways of azo dyes: Toward an optimization of Electro-Fenton treatment. Chemosphere 161, 308-318

Li, H., Lei, H., Yu, Q., Li, Z., Feng, X., Yang, B., 2010b. Effect of low frequency ultrasonic irradiation on the sonoelectro-Fenton degradation of cationic red X-GRL. Chem. Eng. J. $160(2), 417-422$.

Li, H., Zhu, X., Ni, J., 2010a. Inactivation of Escherichia coli in $\mathrm{Na}_{2} \mathrm{SO}_{4}$ electrolyte using boron-doped diamond anode. Electrochim. Acta 56 (1), 448-453.

Liang, L, An, Y.R., Yu, F.K., Liu, M.M, Ren, G.B., Zhou, M.H. 2016. Novel rolling-made gas-diffusion electrode loading trace transition metal for efficient heterogeneous electroFenton-like. J. Environ. Chem. Eng. 4, 4400-4408. 
Lin, H., Zhang, H., Wang, X., Wang, L., Wu, J., 2014. Electro-Fenton removal of Orange II in a divided cell: Reaction mechanism, degradation pathway and toxicity evolution. Sep. Purif. Technol. 122, 533-540.

Liu, X-W., Sun, X-F., Li, D-B., Li, W-W., Huang, Y-X., Sheng, G-P., Yu, H-Q., 2012. Anodic Fenton process assisted by a microbial fuel cell for enhanced degradation of organic pollutants. Water Res. 46 (14), 4371-4378.

Lounis, M., Samar, M.E., Hamdaoui, O., 2016. Sono-electrochemical degradation of Orange $\mathrm{G}$ in pure water, natural water, and seawater: effect of operating parameters. Desalination Water Treat. 57(47), 22533-22542

Ma, L., Zhou, M.H., Ren, G.B., Yang, W.L., Liang, L., 2016. A highly energy-efficient flowthrough electro-Fenton process for organic pollutants degradation. Electrochim. Acta 200, $222-230$

Magario, I., García Einschlag, F.S., Rueda, E.H., Zygadlo, J., Ferreira, M.L., 2012. Mechanisms of radical generation in the removal of phenolderivatives and pigments using different Fe-based catalytic systems. J. Mol. Catal. A: Chem.352, 1-20.

Malik, P.K., 2003. Use of activated carbons prepared from sawdust and rice-husk for adsorption of acid dyes: a case study of Acid Yellow 36. Dyes Pigments 56 (3), 239-249.

Mane, V.S., Mall, I.D., Srivastava, V.C., 2007. Use of bagasse fly ash as an adsorbent for the removal of brilliant green dye from aqueous solution. Dyes Pigments 73 (3), 269-278.

Martínez, S.S., Uribe, E.V., 2012. Enhanced sonochemical degradation of azure B dye by the electroFenton process. Ultrason.Sonochem.19 (1), 174-178.

Martínez-Huitle, C.A., Brillas, E., 2009.Decontamination of wastewaters containing synthetic organic dyes by electrochemical methods: A general review. Appl. Catal. B: Environ. 87 (3-4), 105-145.

Martínez-Huitle, C.A., dos Santos, E.V., de Araújo, D.M., Panizza, M., 2012. Applicability of diamond electrode/anode to the electrochemical treatment of areal textile effluent. J. Electroanal. Chem. 674, 103-107.

Mathur, N., Bhatnagar, P., Bakre, P., 2005. Assessing mutagenicity of textile dyes from pali (Rajasthan) using ames bioassay. Appl. Ecology Environ. Res. 4 (1), 111-118.

Medvedev, Z.A., Crowne, H.M., Medvedeva, M.N., 1988. Age related variations of hepato carcinogenic effect of azo dye (3'-MDAB) as linked to the level of hepatocyte polyploidization. Mech. Ageing Dev. 46 (1-3), 159-174.

Migliorini, F.L., Braga, N.A., Alves, S.A., Lanza, M.R.V., Baldan, M.R., Ferreira, N.G., 2011. Anodic oxidation of wastewater containing the Reactive Orange 16 Dye using heavily boron-doped diamond electrodes. J. Hazard. Mater.192 (3), 1683-1689.

Miled, W., Said, A., Roudseli, S., 2010. Decolorization of high polluted textile wastewater by indirect electrochemical oxidation process. JTATM 6 (3), 1-6. 
Moreira, F.C., Garcia-Segura, S., Vilar, V.J.P., Boaventura, R.A.R., Brillas, E., 2013. Decolorization and mineralization of Sunset Yellow FCF azo dye by anodic oxidation, electro-Fenton, UVA photoelectro-Fenton and solar photoelectro-Fenton processes. Appl. Catal. B: Environ. 142, 877-890.

Murati, M., Oturan, N., Aaron, J-J., Dirany, A., Tassin, B., Zdravkovski, Z., Oturan, M.A., 2012. Degradation and mineralization of sulcotrione and mesotrione in aqueous medium by the electro-Fenton process: a kinetic study. Environ. Sci. Pollut. Res. 19 (5), 15631573.

Muruganandham, M., Swaminathan, M., 2004. Decolourisation of Reactive Orange 4 by Fenton and photo-Fenton oxidation technology. Dyes Pigments 63 (3), 315-321

Murugananthan, M., Yoshihara, S., Rakuma, T., Uehara, N., Shirakashi, T., 2007. Electrochemical degradation of 17b-estradiol (E2) at boron-doped diamond (Si/BDD) thin film electrode. Electrochim. Acta 52 (9), 3242-3249.

Namasivayam, C., Kavitha, D., 2002. Removal of Congo Red from water by adsorption onto activated carbon prepared from coir pith, an agricultural solid waste. Dyes Pigments 54 (1), 47-58.

Nava, J.L., Quiroz, M.A., Martínez-Huitle, C.A., 2008. Electrochemical treatment of synthetic wastewaters containing alphazurine A dye: Role of Electrode material in the colour and cod removal. J. Mex. Chem. Soc. 52 (4), 249-255.

Neyens, E., Baeyens, J., 2003. A review of classic Fenton's peroxidation as an advanced oxidation technique. J. Hazard. Mater.B98 (1-3), 33-50.

Nidheesh, P.V., 2015. Heterogeneous Fenton catalysts for the abatement of organic pollutants from aqueous solution: a review. RSC Adv. 5, 40552-40577.

Nidheesh, P.V., Gandhimathi, R., 2012. Trends in electro-Fenton process for water and wastewater treatment: An overview. Desalination 299, 1-15.

Nidheesh, P.V., Gandhimathi, R., 2014a. Removal of rhodamine B from aqueous solution using graphite- graphite electro Fenton system. Desalination Water Treat. 52, 1872-1877.

Nidheesh, P.V., Gandhimathi, R., 2014b.Comparative removal of rhodamine B from aqueous solution by electro Fenton and electro Fenton like processes. Clean- Soil, Air, Water. 42(6), 779-784.

Nidheesh, P.V., Gandhimathi, R., 2014c. Effect of solution pH on the performance of three electrolytic advanced oxidation processes for the treatment of textile wastewater and sludge characteristics. RSC Adv. 4, 27946-27954.

Nidheesh, P.V., Gandhimathi, R., 2014d. Electrolytic removal of Rhodamine B from aqueous solution by peroxicoagulation process. Environ. Sci. Pollut. Res. 21, 8585-8594.

Nidheesh, P.V., Gandhimathi, R., 2015a. Electro Fenton oxidation for the removal of Rhodamine B from aqueous solution in a bubble column reactor under continuous mode. Desalination Water Treat. 55, 263-273. 
Nidheesh, P.V., Gandhimathi, R., 2015b. Textile Wastewater Treatment by Electro-Fenton Process in Batch and Continuous Modes. J. Hazard. Toxic Radioact. Waste 19(3), 04014038.

Nidheesh, P.V., Gandhimathi, R., Ramesh, S.T., 2013. Degradation of dyes from aqueous solution by Fenton processes: A Review. Environ. Sci. Pollut. Res. 20, 2099-2132.

Nidheesh, P.V., Gandhimathi, R., Sanjini, N.S., 2014b. $\mathrm{NaHCO}_{3}$ enhanced Rhodamine B removal from aqueous solution by graphite-graphite electro Fenton system. Sep. Purif. Technol. 132, 568-576.

Nidheesh, P.V., Gandhimathi, R., Velmathi, S., Sanjini, N.S., 2014a. Magnetite as a heterogeneous electro Fenton catalyst for the removal of Rhodamine B from aqueous solution. RSC Adv.4, 5698-5708.

Olvera-Vargas, H., Cocerva, T., Oturan, N., Buisson, D., Oturan, M.A., 2016a. BioelectroFenton: A sustainable integrated process for removal of organic pollutants from water: Application to mineralization of metoprolol. Journal of Hazardous Materials 319 (2016) 13-23.

Olvera-Vargas, H., Oturan, N., Buisson, D., Oturan, M.A., 2016b. A coupled Bio-EF process for mineralization of the pharmaceuticals Furosemide and Ranitidine: feasibility assessment. Chemosphere, 155, 606-613.

Olvera-Vargas, H., Oturan, N., Aravindakumar, C.T., Sunil Paul, M.M., Sharma, V.K., Oturan, M.A., 2014. Electro-oxidation of the dye azure B: kinetics, mechanism, and byproducts. Environ. Sci. Pollut. Res. 21, 8379-8386.

Oturan, M.A. Pinson, J., 1995. Hydroxylation by electrochemically generated ${ }^{\circ} \mathrm{OH}$ radicals. Mono- and polyhydroxylation of benzoic acid: products and isomers' distribution. J. Phys. Chem. 99(38), 13948-13954.

Oturan, M.A., 2000. An ecologically effective water treatment technique using electrochemically generated hydroxyl radicals for in situ destruction of organic pollutants: Application to herbicide 2,4-D. J. Appl. Electrochem. 30, 475-482.

Oturan, M.A., Aaron, J.-J., 2014. Advanced oxidation processes in water/wastewater treatment: Principles and applications. A review. Crit. Rev. Env. Sci. Technol. 44, 25772641.

Oturan, M.A., Edelahi, M.C., Oturan, N., El Kacemi, K., Aaron, J-J., 2010a. Kinetics of oxidative degradation/mineralization pathways of the phenylurea herbicides diuron, monuron and fenuron in water during application of the electro-Fenton process. Appl. Catal. B: Environ. 97 (1-2), 82-89.

Oturan, M.A., Guivarch, E., Oturan, N., Sirés, I., 2008a. Oxidation pathways of malachite green by $\mathrm{Fe}^{3+}$-catalyzed electro-Fenton process. Appl. Catal. B: Environ. 82 (3-4), 244254. 
Oturan, M.A., Oturan, N., Lahitte, C., Trevin, S., 2001. Production of hydroxyl radicals by electrochemically assisted Fenton's reagent. Application to the mineralization of an organic micropollutant, the pentachlorophenol. J. Electroanal. Chem., 507 (1-2), 96-102.

Oturan, M.A., Peiroten, J., Chartrin, P., Acher, A.J., 2000. Complete destruction of pNitrophenol in aqueous medium by electro-Fenton method. Environ. Sci. Technol. 34 (16), 3474-3479.

Oturan, M.A., Sirés, I., Oturan, N., Pérocheau, S., Laborde, J-L., Trévin, S., 2008b. Sonoelectro-Fenton process: A novel hybrid technique for the destruction of organic pollutants in water. J. Electroanal. Chem. 624 (1-2), 329-332.

Oturan, M.A., Oturan, N., Aaron, J.-J., 2004.Treatment of organic micropollutants in aqueous medium by advanced oxidation process. Actual. Chimique 277-278, 57-64

Oturan, N., Brillas, E., Oturan, M.A., 2012. Unprecedented total mineralization of atrazine and cyanuric acid by anodic oxidation and electro-Fenton with a boron-doped diamond anode. Environ. Chem. Lett., 10(2), 165-170.

Oturan, N., Zhou, M., Oturan, M.A., 2010b. Metomyl Degradation by electro-Fenton and electro-Fenton-like processes: A kinetics study of the effect of the nature and concentration of some transition metal ions as catalyst. J. Phys. Chem. A 114 (39),1060510611.

Özcan, A., Oturan, M.A., Oturan, N., Sahin, Y., 2009b. Removal of Acid Orange 7 from water by electrochemically generated Fenton's reagent. J. Hazard. Mater.163 (2-3), 12131220.

Özcan, A., Sahin, Y., Oturan, M.A., 2008b. Removal of propham from water by using electro-Fenton technology: Kinetics and mechanism. Chemosphere 73 (5), 737-744.

Özcan, A., Sahin, Y., Oturan, M.A., 2013. Complete removal of the insecticide azinphos methyl from water by the electro-Fenton method A kinetic and mechanistic study. Water Res. 47 (3), 1470-1479.

Özcan, A., Sahin, Y., Koparal, A.S., Oturan, M.A., 2008a. Propham mineralization in aqueous medium by anodic oxidation using boron-doped diamond anode: Influence of experimental parameters on degradation kinetics and mineralization efficiency. Water Res. 42 (12), 2889- 2898.

Özcan, A., Sahin, Y., Koparal, A.S., Oturan, M.A., 2009a. A comparative study on the efficiency of electro-Fenton process in the removal of propham from water. Appl. Catal. B: Environ. 89 (3-4), 620-626.

Özcan, A., Sahin, Y., Koparal A.S., Oturan, M.A., 2008c. Carbon sponge as a new cathode material for the electro-Fenton process: Comparison with carbon felt cathode and application to degradation of synthetic dye basic blue 3 in aqueous medium. J. Electroanal. Chem. 616 (1-2), 71-78. 
Panizza, M., Barbucci, A., Ricotti, R., Cerisola, G., 2007. Electrochemical degradation of methylene blue. Sep. Purif. Technol. 54, 382-387.

Panizza, M., Cerisola, G., 2001. Removal of organic pollutants from industrial wastewater by electrogenerated Fenton's reagent. Water Res. 35 (16), 3987-3992.

Panizza, M., Cerisola, G., 2008. Electrochemical degradation of methyl red using BDD and $\mathrm{PbO}_{2}$ anodes. Ind. Eng. Chem. Res. 47 (18), 6816-6820.

Panizza, M., Cerisola, G., 2009. Direct and mediated anodic oxidation of organic pollutants. Chem. Rev., 109 (2009) 6541-6569.

Panizza, M., Oturan, M.A., 2011. Degradation of Alizarin Red by electro-Fenton process using a graphite-felt cathode. Electrochim. Acta 56 (20), 7084-7087.

Peralta-Hernández, J.M., Martínez-Huitle, C.A., Guzmán-Mar, J.L., Hernández-Ramírez, A., 2009. Recent advances in the application of electro-Fenton and photoelectro-Fenton process for removal of synthetic dyes in wastewater treatment. J. Environ. Eng. Manage. 19 (5), 257-265.

Peralta-Hernández, J.M., Meas-Vong, Y., Rodríguez, F.J., Chapman, T.W., Maldonado, M.I., Godínez, L.A., 2008. Comparison of hydrogen peroxide-based processes for treating dyecontaining wastewater: Decolorization and destruction of Orange II azo dye in dilute solution. Dyes Pigments 76 (3), 656-662.

Percy, A.J., Moore, N., Chipman, J.K., 1989. Formation of nuclear anomalies in rat intestine by benzidine and its biliary metabolites. Toxicol. 57 (2), 217-223.

Petrucci, E., Montanaro, D., 2011. Anodic oxidation of a simulated effluent containing Reactive Blue 19 on a boron-doped diamond electrode. Chem. Eng. J. 174 (2-3), 612-618.

Pignatello, J.J.; Oliveros, E., Mackay, A., 2006. Advanced oxidation processes for organic contaminant destruction based on the Fenton reaction and related chemistry. Crit. Rev. Environ. Sci. Technol. 36 (1), 1-84.

Ponnusami, V., Vikram, S., Srivastava, S.N., 2008. Guava (Psidium guajava) leaf powder: Novel adsorbent for removal of methylene blue from aqueous solutions. J. Hazard. Mater.152 (1), 276-286.

Pradhan, A.A., Gogate, P.R., 2010. Degradation of p-nitrophenol using acoustic cavitation and Fenton chemistry. J. Hazard. Mater.173 (1-3), 517-522.

Rabaey, K., Rozendal, R.A., 2010. Microbial electrosynthesis- revisiting the electrical route for microbial production. Nature Rev. Microbiol. 8, 706-716.

Ramachandran, R., Saraswathi, R., 2011. Sonoelectrochemical studies on mass transport in some standard redox systems. Russ. J. Electrochem. 47 (1), 15-25.

Ramírez, C., Saldana, A., Hernández, B., Acero, R., Guerra, R., Garcia-Segura, S., Brillas, E., Peralta-Hernández, J.M., 2013. Electrochemical oxidation of methyl orange azo dye at pilot flow plant using BDD technology. J. Ind. Eng. Chem. 19 (2), 571-579. 
Rauf, M.A., Meetani, M.A., Hisaindee, S., 2011. An overview on the photocatalytic degradation of azo dyes in the presence of $\mathrm{TiO}_{2}$ doped with selective transition metals. Desalination 276 (1-3), 13-27.

Ren, G.B., Zhou, M.H., Liu, M.M., Ma, L., Yang, H.J., 2016. A novel vertical-flow electroFenton reactor for organic wastewater treatment. Chem. Eng. J. 298, 55-67.

Rodriguez, J., Rodrigo, M.A., Panizza, M., Cerisola, G., 2009. Electrochemical oxidation of Acid Yellow 1 using diamond anode. J. Appl. Electrochem. 39 (11), 2285-2289.

Rosales, E., Iglesias, O., Pazos, M., Sanromán, M.A., 2012. Decolourisation of dyes under electro-Fenton process using Fe alginate gel beads. J. Hazard. Mater.213-214, 369-377.

Roshini, P.S., Gandhimathi, R., Ramesh, S.T., Nidheesh, P.V., 2018. Combined electroFenton and biological processes for the treatment of industrial textile effluent: Mineralization and toxicity analysis. J. Hazard. Toxic Radioact. Waste 21(4), doi: 10.1061/(ASCE)HZ.2153-5515.0000370

Ruiz, E.J., Arias, C., Brillas, E., Hernández-Ramírez, A., Peralta-Hernández, J.M., 2011b. Mineralization of Acid Yellow 36 azo dye by electro-Fenton and solar photoelectroFenton processes with a boron-doped diamond anode. Chemosphere 82 (4), 495-501.

Ruiz, E.J., Hernández-Ramírez, A., Peralta-Hernández, J.M., Arias, C., Brillas, E., 2011a. Application of solar photoelectro-Fenton technology to azo dyes mineralization: Effect of current density, $\mathrm{Fe}^{2+}$ and dye concentrations. Chem. Eng. J. 171 (2), 385- 392.

Saez, C., Panizza, M., Rodrigo, M.A., Cerisola, G., 2007. Electrochemical incineration of dyes using a boron-doped diamond anode. J.Chem. Technol. Biot. 82 (6), 575-581.

Şahinkaya, S., 2013. COD and color removal from synthetic textile wastewater by ultrasound assisted electro-Fenton oxidation process. J. Ind. Eng. Chem. 19 (2), 601-605.

Salari, D., Niaei, A., Khataee A., Zarei, M., 2009.Electrochemical treatment of dye solution containing C.I. basic yellow 2 by the peroxi-coagulation method and modeling of experimental results by artificial neural networks.J. Electroanal. Chem. 629 (1-2), 117125.

Salazar, R., Garcia-Segura, S., Ureta-Zãnartu, M.S., Brillas, E., 2011. Degradation of disperse azo dyes from water by solar photoelectro-Fenton. Electrochim. Acta 56 (18), 6371-6379.

Salazar, R., Ureta-Zañartu, M.S., 2012. Degradation of acid violet 7 and reactive black 5 in water by electro-Fenton and photo electro-Fenton. J. Chil. Chem. Soc. 57 (1), 999-1003.

Saltmiras, D.A., Lemley, A.T., 2000. Degradation of ethylene thiourea (ETU) with three Fenton treatment processes.J. Agric.Food Chem. 48 (12), 6149-6157.

Sandhya, S., Sarayu, K., Swaminathan, K., 2008.Determination of kinetic constants of hybrid textile wastewater treatment system. Bioresource Technol. 99 (13), 5793-5797. 
Scialdone, O., 2009. Electrochemical oxidation of organic pollutants in water at metal oxide electrodes: A simple theoretical model including direct and indirect oxidation processes at the anodic surface. Electrochim. Acta 54 (26), 6140-6147.

Scialdone, O., Galia, A., Sabatino, S., 2013. Electro-generation of $\mathrm{H}_{2} \mathrm{O}_{2}$ and abatement of organic pollutant in water by an electro-Fenton process in a microfluidic reactor.Electrochem.Commun. 26, 45-47.

Sekar, P., Hari Prasad, S., Decca Raman, M., 2009. Effect of textile dye industry effluent on the nutritive value of fresh water female crab Spiralothelphusa hydrodroma (Herbst). J. Appl. Sci. Res. 5 (11), 2041-2048.

Siddique, M., Farooq, R., Khan, Z.M., Khan, Z., Shaukat, S.F., 2011. Enhanced decomposition of reactive blue 19 dye in ultrasound assisted electrochemical reactor. Ultrason. Sonochem.18 (1), 190-196.

Sirés, I., Brillas, E., Oturan, M.A., Rodrigo, M.A., Panizza, M., 2014. Electrochemical advanced oxidation processes: today and tomorrow. A review. Environ. Sci. Pollut. Res. 21, 8336-8367.

Sirés, I., Cabot, P.L., Centellas, F., Garrido, J.A., Rodríguez, R.M., Arias, C., Brillas, E., 2006. Electrochemical degradation of clofibric acid in water by anodic oxidation Comparative study with platinum and boron-doped diamond electrodes. Electrochim. Acta $52(1), 75-85$.

Sirés, I., Guivarch, E., Oturan, N., Oturan, M.A., 2008. Efficient removal of triphenylmethane dyes from aqueous medium by in situ electrogenerated Fenton's reagent at carbon-felt cathode. Chemosphere 72 (4), 592-600.

Sivasankar, T., Moholkar, V.S., 2010. Physical insight into the sonochemical degradation of 2,4-dichlorophenol. Environ. Technol. 31 (14), 1483-1494.

Solano, A.M.S., Garcia-Segura, S., Martínez-Huitle, C.A., Brillas, E., 2015. Degradation of acidic aqueous solutions of the diazo dye Congo Red by photo-assisted electrochemical processes based on Fenton's reaction chemistry. Appl. Catal. B: Environ. 168-169, 559571

Song, S., Fan, J., He, Z., Zhan, L., Liu, Z., Chen, J., Xu, X., 2010. Electrochemical degradation of azo dye C.I. Reactive Red 195 by anodic oxidation on $\mathrm{Ti} / \mathrm{SnO}_{2}-\mathrm{Sb} / \mathrm{PbO}_{2}$ electrodes. Electrochim. Acta 55 (11), 3606-3613.

Sopaj F., Rodrigo M.A., Oturan N., Podvorica F.I., Pinson J., Oturan M.A., 2015. Influence of the anode materials on the electrochemical oxidation efficiency. Application to oxidative degradation of the pharmaceutical amoxicillin. Chem. Eng. J. 262, 286-294.

Sopaj F., Oturan N., Pinson J., Podvorica F., Oturan M.A., 2016. Effect of the anode materials on the efficiency of the electro-Fenton process for the mineralization of the antibiotic sulfamethazine. Appl. Catal. B: Environ. 199, 331-341.

Srivastava, S., Sinha, R., Roy, D., 2004. Toxicological effects of malachite green. Aquat. Toxicol. 66 (3), 319-329. 
Sun, J., Lu, H., Du, L., Lin, H., Li, H., 2011. Anodic oxidation of anthraquinone dye Alizarin Red S at Ti/BDD electrodes. Appl. Surf. Sci. 257 (15), 6667-6671.

Sun, S.P., Li, C.J., Sun, J.H., Shi, S.H., Fan, M.H., Zhou, Q., 2009. Decolorization of an azo dye Orange $\mathrm{G}$ in aqueous solution by Fenton oxidation process: Effect of system parameters and kinetic study. J. Hazard. Mater.161 (2-3), 1052-1057.

Suslick, K.S., 1989. The chemical effects of ultrasound. Sci. Am. 260, 80-87.

Suteu, D., Bilba, D., 2005. Equilibrium and kinetic study of reactive dye brilliant red HE-3B adsorption by activated charcoal. Acta Chim. Slov. 52, 73-79.

Tang, W.Z., Huang, C.P., 1996. 2,4-dichlorophenol oxidation kinetics by Fenton's reagent. Environ. Technol. 17 (12), 1371-1378.

Umbuzeiro, G.A., Freeman, H., Warren, S.H., Kummrow, F., Claxton, L.D., 2005. Mutagenicity evaluation of the commercial product CI Disperse Blue 291 using different protocols of the Salmonella assay. Food Chem. Toxicol. 43 (1), 49-56.

Vasudevan, S., Oturan, M.A., 2014. Electrochemistry as cause and cure in water pollution. An Overwiew. Environ. Chem. Lett. 12(1), 97-108.

Venu, D., Gandhimathi, R., Nidheesh, P.V., Ramesh, S.T., 2014. Treatment of stabilized landfill leachate using peroxicoagulation process. Sep. Purif. Technol. 129, 64-70.

Venu, D., Gandhimathi, R., Nidheesh, P.V., Ramesh, S.T., 2016. Effect of solution pH on leachate treatment mechanism of peroxicoagulation process. J. Hazard. Toxic Radioact. Waste 20 (3), 06016001.

Wang, A., Qu, J., Liu, H., Ru, J., 2008b. Mineralization of an azo dye Acid Red 14 by photoelectro-Fenton process using an activated carbon fiber cathode. Appl. Catal. B: Environ. 84 (3-4), 393-399.

Wang, C.T., Chou, W.L., Chung, M.H., Kuo, Y.M., 2010. COD removal from real dyeing wastewater by electro-Fenton technology using an activated carbon fiber cathode. Desalination 253 (1-3), 129-134.

Wang, C-T., Hu, J-L., Chou, W-L., Kuo, Y-M., 2008a. Removal of color from real dyeing wastewater by Electro-Fenton technology using a three-dimensional graphite cathode. J. Hazard. Mater.152 (2), 601-606.

Wang, Q., Jin, T., Hu, Z.X., Zhou, L., Zhou, M.H., 2013. TiO $-\mathrm{TTs}_{2} / \mathrm{SnO}_{2}-\mathrm{Sb}$ anode for efficient electrocatalytic degradation of organic pollutants: Effect of $\mathrm{TiO}_{2}$-NTs architecture. Sep. Purif. Technol. 102, 180-186.

Wang, Q., Lemley, A.T., 2002. Oxidation of diazinon by anodic Fenton treatment. Water Res. 36 (13), 3237-3244.

Wang, Q., Lemley, A.T., 2003. Oxidative degradation and detoxification of aqueous carbofuran by membrane anodic Fenton treatment. J. Hazard. Mater.B98 (1-3), 241-255.

Wang, Z., Qi, J., Feng, Y., Li, K., Li, X., 2014a. Fabrication and electrocatalytic performance of a novel particle electrode. Catal. Commun. 46, 165-168. 
Wang, Z., Qi, J., Feng, Y., Li, K., Li, X., 2014b. Preparation of catalytic particle electrodes from steel slag and its performance in a three-dimensional electrochemical oxidation system. J. Ind. Eng. Chem. 20(5), 3672-3677

Wells, C.F., Salam, M.A., 1965. Hydrolysis of ferrous ions: A kinetic method for determination of the Fe(II) species. Nature 205, 690-692.

Wells, C.F., Salam, M.A., 1968. The effect of $\mathrm{pH}$ on the kinetics of the reaction of iron(II) with hydrogen peroxide in perchlorate media. J. Chem. Soc. A 1968, 24-29.

Xu, X., Chen, J., Zhang, G., Song, Y., Yang, F., 2014. Homogeneous electro-Fenton oxidative degradation of reactive brilliant blue using a graphene doped gas-diffusion cathode. Int. J. Electrochem. Sci. 9, 569-579.

Yang, W., Zhou, M.H., Cai, J. J., Liang, L., Ren, G.B., 2017. Ultrahigh yield of hydrogen peroxide on graphite felt cathode modified with electrochemically exfoliated graphene. J. Mater. Chem. A 5, 8070-8080.

Yao, Y., Zhao, C., Zhao, M., Wang, X., 2013. Electrocatalytic degradation of methylene blue on $\mathrm{PbO}_{2}-\mathrm{ZrO}_{2}$ nanocomposite electrodes prepared by pulse electrodeposition. J. Hazard. Mater. 263 (2), 726-734.

Yavuz, Y., Shahbazi, R., 2012. Anodic oxidation of Reactive Black 5 dye using boron doped diamond anodes in a bipolar trickle tower reactor. Sep. Purif. Technol. 85, 130-136.

Yu, F.K., Zhou, M.H., Yu, X.M. 2015. Cost-effective electro-Fenton using modified graphite felt that dramatically enhanced on $\mathrm{H}_{2} \mathrm{O}_{2}$ electro-generation without external aeration. Electrochim. Acta 163, 182-189.

Yue, L., Wang, K., Guo, J., Yang, J., Luo, X., Lian, J., Wang, L., 2014. Enhanced electrochemical oxidation of dye wastewater with $\mathrm{Fe}_{2} \mathrm{O}_{3}$ supported catalyst. J. Ind. Eng. Chem. 20 (2), 725-731.

Zarei, M., Khataee, A.R., Ordikhani-Seyedlar, R., Fathinia, M., 2010b. Photoelectro-Fenton combined with photocatalytic process for degradation of an azo dye using supported $\mathrm{TiO}_{2}$ nanoparticles and carbon nanotube cathode: Neural network modeling. Electrochim. Acta 55 (24), 7259-7265.

Zarei, M., Niaei, A., Salari, D., Khataee, A., 2010a. Removal of four dyes from aqueous medium by the peroxi-coagulation method using carbon nanotube-PTFE cathode and neural network modeling. J. Electroanal. Chem. 639 (1-2), 167-174.

Zarei, M., Salari, D., Niaei, A., Khataee, A., 2009. Peroxi-coagulation degradation of C.I. basic yellow 2 based on carbon-PTFE and carbon nanotube-PTFE electrodes as cathode. Electrochim. Acta 54 (26), 6651-6660.

Zhang, C., Jiang, Y., Li, Y., Hu, Z., Zhou, L., Zhou, M., 2013. Three-dimensional electrochemical process for wastewater treatment: A general review. Chem. Eng. J. 228, 455-467. 
Zhang, C., Zhou, L., Yang, J., Yu, X., Jiang, Y., Zhou, M., 2014. Nanoscale zero-valent iron/AC as heterogeneous Fenton catalysts in three-dimensional electrode system. Environ. Sci. Pollut. Res. 21, 8398-8405

Zhang, Y., Wang, Y., Angelidaki, I., 2015. Alternate switching between microbial fuel cell and microbial electrolysis cell operation as a new method to control $\mathrm{H}_{2} \mathrm{O}_{2}$ level in Bioelectro-Fenton system. J. Power Source. 291,108-116.

Zhao, G., Gao, J., Shi, W., Liu, M., Li, D., 2009. Electrochemical incineration of high concentration azo dye wastewater on the in situ activated platinum electrode with sustained microwave radiation. Chemosphere 77 (2), 188-193.

Zhao, X., Liu, S., Huang, Y., 2016. Removing organic contaminants by an electro-Fenton system constructed with graphene cathode. Toxicol. Environ. Chem. 98, 530-539

Zhou, L. Zhou, M., Zhang, C., Jiang, Y., Bi, Z.H., Yang, J., 2013. Electro-Fenton degradation of p-nitrophenol using the anodized graphite felts. Chem. Eng. J., 233, 185-192.

Zhou, L., Zhou, M., Hu, Z., Bi, Z., Serrano, K.G., 2014. Chemically modified graphite felt as an efficient cathode in electro-Fenton for p-nitrophenol degradation. Electrochim. Acta 140, 376-383.

Zhou, M., Yu, Q., Lei, L., Barton, G., 2007. Electro-Fenton method for the removal of methyl red in an efficient electrochemical system. Sep. Purif. Technol. 57 (2), 380-387.

Zhou, M.H., Liu, L., Jiao, Y. L., Wang, Q., Tan, Q.Q., 2011b. Treatment of high-salinity reverse osmosis concentrate by electrochemical oxidation on BDD and DSA electrodes. Desalination 277, 201-206.

Zhou, M.H., Särkkä H., Sillanpää M.A. 2011a. Comparative experimental study on methyl orange degradation by electrochemical oxidation on BDD and MMO electrodes. Sep. Purif. Technol. 78, 290-297.

Zhu, X., Logan B.E., 2013. Using single-chamber microbial fuel cells as renewable power sources of electro-Fenton reactors for organic pollutant treatment. J. Hazard. Mater.252253, 198-203.

Zhu, X., Ni, J., 2009. Simultaneous processes of electricity generation and p-nitrophenol degradation in a microbial fuel cell. Electrochem. Commun. 11 (2), 274-277. 